OPEN ACCESS

Edited by: Peng Qu,

National Institutes of Health $(\mathrm{NIH})$,

United States

Reviewed by:

Francesca Romana Ponziani, Fondazione Policlinico Universitario Agostino Gemelli IRCCS, Italy Mingxiao Feng, Johns Hopkins University, United States

*Correspondence: Riming Huang huangriming@scau.edu.cn Lianxiang LuO luolianxiang321@gdmu.edu.cn

${ }^{+}$These authors have contributed equally to this work

Specialty section: This article was submitted to Cancer Immunity and Immunotherapy,

a section of the journal

Frontiers in Immunology

Received: 30 September 2020 Accepted: 23 November 2020 Published: 07 January 2021

Citation:

Qiu Q, Lin Y, Ma Y, Li X, Liang J, Chen Z, Liu K, Huang Y, Luo H, Huang $R$ and $L u o ~ L$ (2021) Exploring the Emerging Role of the Gut Microbiota and Tumor Microenvironment in Cancer Immunotherapy.

Front. Immunol. 11:612202. doi: 10.3389/fimmu.2020.612202

\section{Exploring the Emerging Role of the Gut Microbiota and Tumor Microenvironment in Cancer Immunotherapy}

\author{
Qin Qiu ${ }^{1 \dagger}$, Yuqi Lin ${ }^{2 \dagger}$, Yucui Ma ${ }^{3 \dagger}$, Xiaoling Li ${ }^{4}$, Juan Liang ${ }^{1}$, Zhiyan Chen ${ }^{5}$, Kaifeng Liu ${ }^{5}$, \\ Yuge Huang ${ }^{6}$, Hui Luo ${ }^{3}$, Riming Huang ${ }^{2 *}$ and Lianxiang Luo ${ }^{3,7,8 *}$ \\ ${ }^{1}$ Graduate School, Guangdong Medical University, Zhanijang, China, ${ }^{2}$ Guangdong Provincial Key Laboratory of Food Quality \\ and Safety, College of Food Science, South China Agricultural University, Guangzhou, China, ${ }^{3}$ The Marine Biomedical \\ Research Institute, Guangdong Medical University, Zhanjiang, China, ${ }^{4}$ Animal Experiment Center, Guangdong Medical \\ University, Zhanjiang, China, 5 The First Clinical College, Guangdong Medical University, Zhanjiang, China, 6 Department of \\ Pediatrics, The Affiliated Hospital of Guangdong Medical University, Zhanjiang, China, ${ }^{7}$ The Marine Biomedical Research \\ Institute of Guangdong Zhanjiang, Zhanijang, China, ${ }^{8}$ Southern Marine Science and Engineering Guangdong Laboratory \\ (Zhanjiang), Zhanjiang, China
}

The tumor microenvironment (TME) is a complex ecosystem, which includes many different types of cells, abnormal vascular systems, and immunosuppressive cytokines. TME serves an important function in tumor tolerance and escapes from immune surveillance leading to tumor progression. Indeed, there is increasing evidence that gut microbiome is associated with cancer in a variety of ways, as specific microbial signatures are known to promote cancer development and influence safety, tolerability, and efficacy of therapies. Studies over the past five years have shown that the composition of the intestinal microbiota has a significant impact on the efficacy of anticancer immunosurveillance, which contribute to the therapeutic activity of cancer immunotherapies based on targeting cytotoxic $T$ lymphocyte protein 4 (CTLA-4) or programmed cell death protein 1 (PD-1)-programmed cell death 1 ligand 1 (PD-L1) axis. In this review, we mainly discuss the impact of TME on cancer and immunotherapy through immune-related mechanisms. We subsequently discuss the influence of gut microbiota and its metabolites on the host immune system and the formation of TME. In addition, this review also summarizes the latest research on the role of gut microbiota in cancer immunotherapy.

Keywords: tumor microenvironment, gut microbiota, immunotherapy, host immunity, programmed cell death protein 1/programmed cell death 1 ligand 1

\section{INTRODUCTION}

Cancer is a major public health problem with high rates of incidence and mortality (1). Over the past few decades, significant progress has been achieved in the field of cancer treatment, the main treatment methods included surgery, chemotherapy, radiotherapy, target therapy, and immunotherapy, among them, immunotherapy has become a research hotspot in recent years 
among these $(2,3)$. However, the effect of tumor immunotherapy is largely affected by tumor microenvironment (TME) $(4,5)$. The TME consisted of a variety of different cell types, which plays an important role in tumor tolerance and the evasion of immune surveillance (6). Studies have shown that multiple cells in TME play a significant role in tumor immunotherapy, including $\mathrm{T}$ cell, fibroblasts, natural killer (NK) cell, dendritic cells (DCs), and so on (7-9), NK cells stimulate CDC1 to enter into the TME and promote tumor immune control (10). More than 1,000 microorganisms are living in the human gut, called the gut microbiota, which is closely related to a variety of diseases, for example, chronic inflammation, autoimmunity, cancer, and so on $(7,11)$. Gut microbiota can shape TME by regulating the immune and hormonal factors of the whole host (7), in other words, host gut microbiota is emerging as a critical modulator of the TME. It is also reported that regulating gut microbiota can enhance the effect of cancer immunotherapy (12). It is worth mentioning that the metabolites of gut microbiota [such as shortchain fatty acids (SCFAs), lipopolysaccharide, and Gallic acid] also have effects on TME and tumor immunosuppressive therapy (13-15). Besides, gut microbiota acts tumor immunotherapy directly or indirectly through immune-related mechanisms. The gut microbiota has been found to inhibit the cancersuppressing effect of p53 mutations, while antibiotic treatment (elimination of gut microbiota) can restore it (16). Exploring roles of gut microbiota and TME in cancer immunotherapy as well as their interaction based on literature survey, which obtains answer of problems existed in cancer immunotherapy, and clarifies the future research direction of tumor immunotherapy. Meanwhile, it provides a theoretical basis for immunotherapy based on TME and gut microbiota.

\section{THE ROLE OF TME IN CANCER IMMUNOTHERAPY}

TME is composed of immune cells, such as T cells, B cells, and NK cells, a variety of myeloid cell populations including granulocytes, monocytes, macrophages, and DCs, abnormal vasculature and immunosuppressive cytokines, which play different roles in TME $(17,18)$. The progress of cancer growth, invasion, metastasis, drug resistance, and immune escape are affected by TME $(19,20)$. For example, TME promotes the occurrence of hepatocellular carcinoma (HCC) in many ways, mainly in that NK cells and DCs participate in immune escape mechanisms, macrophages are involved in promotion of angiogenesis and tissue remodeling, and the production of cytokines and chemokines lead to persistent inflammationrelated damage (21-23). On the other hand, well expression of co-inhibitory molecules, especially CTLA-4, PD-1 and PD-L1 are associated with immune-system exhaustion and immune tolerance $(24,25)$. The regulation of the TME could be used as an effective strategy to prevent as well as treat cancer (2). The purpose of tumor immunotherapy is to stimulate tumor-specific cytotoxic T lymphocytes (CTLs) and subsequent transports, to enable them to reach and persist in TME in order to identify and eliminate malignant target cells (26). TME show different important effects and mechanisms in the tumor and its immunotherapy with different channels (Figure 1).

\section{Dendritic Cells and T Cells}

$\mathrm{T}$ cells play an irreplaceable role in tumor immunotherapy. $\mathrm{T}$ cells through the $\mathrm{T}$ cell receptor (TCR) to identify major histocompatibility complex class I/II (MHC- I/MHC-II) molecules that existed on the surface of the specific antigen peptide of malignant cells, which plays an important role in defense against cancer. Tumor targets are mainly achieved by releasing the content of cytolytic granules containing perforin and granzyme. To destroy their targets, CTLs must first migrate to tumor sites, infiltrate tumor tissue, interact with cancer cells, and eventually eliminate transformed cells due to trigger effector functions (27). It is indicated that a better prognosis of lung, melanoma, brain, breast, colorectal cancer is associated with that infiltration of T cells, particularly CD8+ T cells infiltrate into the TME $(28,29)$. CD8+ T cell mediated anti-tumor immunity of promising cancer immunotherapy, including DC cancer vaccines, adaptability of reactive $\mathrm{T}$ cell tumor cell metastasis (ACT) and free of disease checkpoint blockade, such as resistance to PD-1, PD-L1, and resisting CTLA-4 (26), PD-1 therapy is associated with the abundance of CD8+ T cells that support tumor invasion, tumor mutation load, and interferon signaling (30).

Although tumor cells have directly present tumor antigens to MHC-I playing a strong part in the effector function of $\mathrm{CD}^{+} \mathrm{T}$ cells, it is necessary that primary $\mathrm{CD}^{+} \mathrm{T}$ cells need to be crosspresented by specialized antigen-presenting cells (especially DCs) to maintain the cytotoxic immune response. TME plays a key role not only in initiating the primary immune response, but also in initiating the acquired immune response $(31,32)$. In fact, DCs in tumors mainly act on $\mathrm{T}$ cells and can be divided into two subgroups: conventional DC type $1(\mathrm{cDC} 1)$ and conventional DC type 2 (cDC2) (33). On the one hand, $\mathrm{cDC} 1$ can attract $\mathrm{T}$ cells in the tumor, to stimulate and magnified the role of tumor specific CD8+ $\mathrm{T}$ cells, meanwhile, which can induce the death of tumor cells and the drainage of tumor antigens to lymph nodes $(34,35)$, where the formation is responsible for the staggered start anti-tumor key DC subtype of CD8+ T cells, so as to achieve the effect of the removal of the tumor (36). On the other hand, conventional type 1 DCs in TME can be induced to support T cell effector function by secreting interleukin-12 (37) and recruiting chemokines such as CCL5 and XCL1 $(38,39)$.

The response will be activated by $\mathrm{cDC} 2$ when $\mathrm{CD} 4^{+} \mathrm{T}$ cells migrate to lymph nodes. Interestingly, regulatory $\mathrm{T}$ cells (Tregs) inhibit tumor-responsive activated $\mathrm{CD} 4^{+} \mathrm{T}$ cells by inhibiting cDC2, and Tregs also inhibit mature DCs and prevent their migration to draining lymph nodes $(40,41)$. The DCs, the main companions of $\mathrm{T}$ cells, not only are crucial for initiating a primary immune response, but also play a vital role in initiating acquired immune response in $\operatorname{TME}(31,32)$. Many researches provide new evidence for the wider role of DCs in tumors, including maintaining and supporting effect function in T-cell responses (30). DCs and T cells complement each other in the role of cancer immunotherapy and play an anti-tumor role 


\section{Tumor microenvironment}

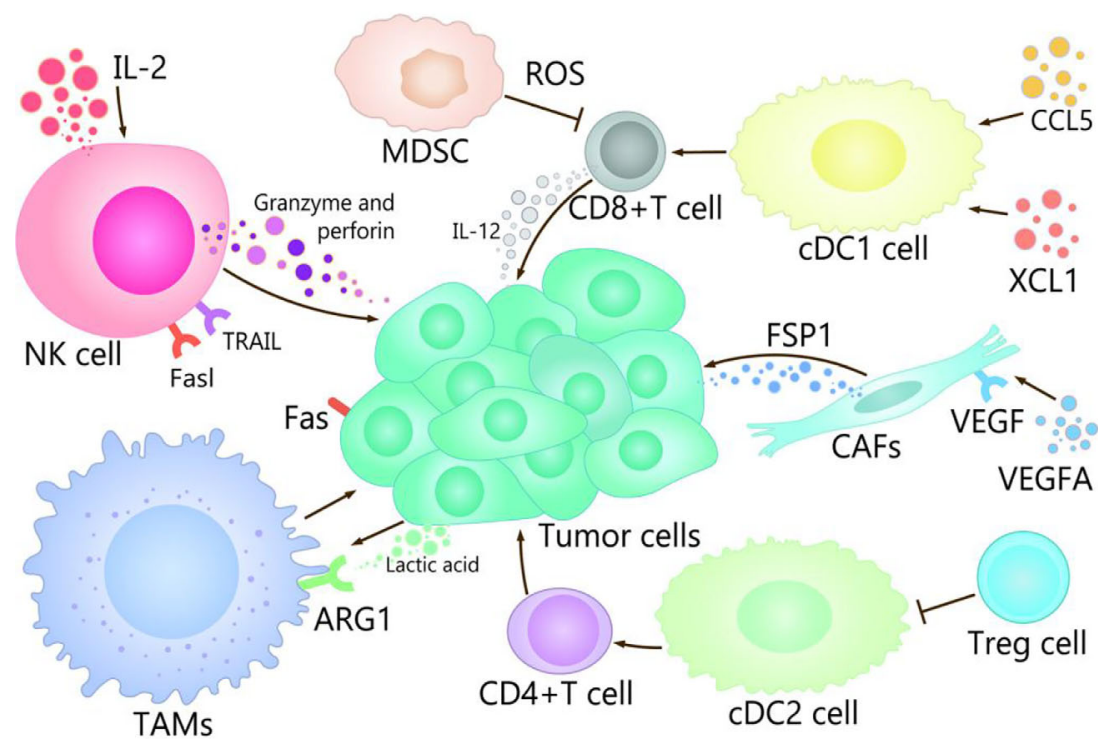

FIGURE 1 | The role of TME in cancer and its immunotherapy. The main cells of the TME in cancer immunity are NK cells, DC cells, CD8 + T cells, Treg cells, fibroblasts, TAMs, and MDSCs. Among them, NK cells induce the death of tumor cells by the ways of releasing perforin and granzyme, secreting tumor necrosis factor-a, and mediating cytotoxicity by TRAIL and Fasl receptors. CDC1 cells are able to promote the differentiation and maturation of CD8 ${ }^{+} \mathrm{T}$ cells, and cDC1 cells can recruit CCL5 and XCL1, which induce the accumulation of CDC1 cells in the TME, thereby improving the immune control of tumors. IL-2 contributes to enhancing the antitumor activity of NK cells. When CD4 + T cells migrate to lymph nodes, cDC2 can activate CD4 ${ }^{+} \mathrm{T}$ cell responses. cDC2 resistant CD4 ${ }^{+} \mathrm{T}$ cells can be inhibited by Treg cells. VEGFA activates fibroblasts, which secrete FSP1. TAMs can promote the growth and metastasis of tumor cells through multiple pathways, lactate produced by cancer and acidification of the microenvironment increase ARG1 expression in TAMs. MDSCs affect the ability to respond to nonspecific stimulation by producing ROS, etc., which leads to the inability of $\mathrm{CD}^{+} \mathrm{T}$ cells combined with $\mathrm{pMHC}$.

together. But many unknown mechanisms remain to be further studied in order to better grasp prospects in cancer therapy.

\section{NK Cell}

Although current tumor immunotherapy mainly focuses on $\mathrm{T}$ cells, NK cells also are gradually being considered as the key target of tumor immunotherapy. NK cell-based therapy is becoming a safe and effective treatment for some cancers (42). The enhanced anti-tumor response mediated by $\mathrm{CD}^{+} \mathrm{T}$ cells was associated with altered the acquired immune response, which related to the interaction between NK cells and immune cells $(43,44)$. In addition, NK cells recognize and mediate direct cytotoxic activity against tumor cells in early cancer (45). NK cells distinguish tumor cells and viral infections of cancer cells by encoding a series of receptor activation and inhibition of receptors (10). The activated receptor and inhibitory receptor signal are balanced to positively promote the activation of NK cells, which induce the target cell death through releasing granzyme and perforin by exocytosis, the cytotoxicity mediated receptor of by TNF-related apoptosis inducing ligand (TRAIL) and Fas ligand (FasL) (46).

$\mathrm{PD}-1$ is mainly expressed on activated T cells, but also on NK cells, called "PD $-1^{+} \mathrm{NK}$ cells" accounting for $25 \%$ of NK cells, whose expression is increased in a variety of cancers indicating a poor prognosis $(47,48)$. Blocking the PD-1/PD-L1 interaction with anti-PD-L1 or PD-L1 antibody restores, could reverse the dysfunctional status of $\mathrm{PD}-1^{+} \mathrm{NK}$ cells and restore the antitumor response of $\mathrm{NK}$ cells $(49,50)$. At the same time, the increase in the frequency and activation of NK cells can enhance the response to anti-PD-1 therapy, and the rescue of NK cell activity can enhance the anti-tumor activity of adaptive $\mathrm{T}$ cells, thus increasing the overall survival rate of patients with multiple types of cancer (44). The anti-tumor activity of NK cells can be enhanced by cytokines, especially IL-2, but with toxic (51). IL-12 has a huge potential for increasing ADCC-mediated NK cell killing activity in solid tumors (52). It has been found that immunomodulatory drugs like lenalidomide can enhance the cytotoxicity mediated by NK cell and ADCC (16). However, in most studies, a small number and impaired function of NK cells isolated from primary tumors were observed, which was mainly due to the accumulation of suppressors in the TME, which inhibited the anti-tumor activity of NK cells and reduced the recruitment and persistence of NK cells in tumor nests (53). The complex interaction of cancer cells and the immune system has great limitations to the immunogenicity of cancer and promotes immunosuppression, which is the key factor affecting the drug resistance and validity of NK cell therapy. Therefore, a deeper understanding of the complex interactions between NK cells and TME in solid tumors will open up new prospects for cancer treatment (54). 


\section{Tumor-Associated Fibroblasts}

Fibroblasts are repeatedly activated by a diverse set of factors secreted from cancer or immune cells, resulting in phenotypic transformation and becoming tumor-associated fibroblasts (CAFs), which are not only the source of immunosuppressive molecules, but also a physical barrier (55). CAFs are indispensable in the immunosuppression within TME and has the role of promoting cancer, thus it has become a target to enhance cancer immunotherapy (56). The occurrence and development of tumors could be inhibited by antifibrotic drugs (57).

CAFs inhibit the activity of CTLs and recruit lymphocytes that produce inflammatory signals to promote cancer progression (58). CAFs can direct or coordinate the infiltration of immune cells directly or through secreted cytokines and surface proteins, or indirectly and coordinate the infiltration of immune cells by depositing various ECM substrates and remodeling matrices, thereby promote cancer $(59,60)$. For example, the protein-1 (FSP1) secreted by fibroblasts, which cause metastasis of colon and breast cancer, and the factor A (VEGFA) induce the development of cancer cell (61). In addition, CAFs promotes resistance to anticancer drugs or therapies and provides protective or proliferative factors in cancer cells (62). Genetic variation has been found in cancerassociated fibroblasts, which is more genetically stable than tumor cells, making it an alternative target for immunotherapy (63). CAFs have several potential therapeutic targets, such as VEGF, which is the most important signal mediating vascular growth, and several VEGF inhibitors are currently being tested in phase I or II trials for colon and lung cancer (60). Pirfenidone, an orally active synthetic anti-fibrotic, which not only reduces the risk of lung cancer in patients with idiopathic pulmonary fibrosis, but also inhibits tumor growth and distant metastasis of refractory breast and pancreatic cancer (64-66). Anti-fibrosis therapy holds great promise.

\section{Tumor-Associated Macrophages and Myeloid-Derived Suppressor Cells}

Tumor-associated macrophages (TAMs), one of the most dominant immune cells in TME, can promote the growth and metastasis of tumor cells in many ways (67). In addition, TAMs in some settings stimulate anti-tumor immunity or kill tumor cells directly (68). Macrophages differentiate into typically activated macrophages (M1), induced by IFN- $\gamma$ and/or lipopolysaccharide (LPS), which is important to host defense and anti-tumor immunity and activated macrophages (M2), induced by IL-4/IL-13, which play a critical role in fibrosis, promote wound healing, dampen inflammation and tumorigenesis $(46,69)$. TAMs play an M2 role to produce high levels of reactive oxygen free radicals, promote DNA damage and genomic instability, tumor infiltration and metastasis, participate in the digestion and reconstruction of extracellular matrix (ECM), inhibit anti-tumor immunity and so on (70). IFN- $\gamma$ and celecoxib inhibits M2 differentiation, thus inhibiting tumor growth (71). Tumor cells release too much tumor-promoting and angiogenic cytokines/chemokines with TAMs and tumor- associated neutrophils (TANs), targeting these mediators and blocking immunosuppressive molecules expressed by tumor cells or tumor-infiltrating immune cells (9).

Myeloid-derived suppressor cells (MDSCs) are also one of the important components of TME (72). MDSCs are an effective inhibitor of innate and adaptive immunity, especially on $\mathrm{T}$ cells $(73,74)$. MDSCs can induce CD ${ }^{+} \mathrm{T}$ cell tolerance, this $\mathrm{CD}^{+} \mathrm{T}$ cell tolerance is one of the major mechanisms of tumor escape. The specific manifestation is that MDSCs induce the nitration of TCR/CD8 complex through the excessive production of reactive oxygen species (ROS) and peroxynitrite in the process of cell-cell direct contact, which leads to the inability of $\mathrm{CD}^{+} \mathrm{T}$ cells to bind to peptide-MHC (pMHC) and affect the ability to respond to non-specific stimulation (75). In addition, MDSCs increase the metabolism of L-arginine (L-Arg) by producing arginase I, which inhibits $\mathrm{T}$ cell-lymphocyte reaction and block T-cell activation by consuming cysteine $(76,77)$.

The stimulating factor 1 receptor (CSF1R) is significantly expressed in MDSCs and TAMs, which cause functionally reprogram the response of macrophage and enhance antigen presentation and anti-tumor $\mathrm{T}$ cell response. Meanwhile, $\mathrm{T}$ cell checkpoint molecules, including PDL1 and CTLA4, are upregulated by CSF1R blockade, thus inhibiting beneficial therapeutic effects, but the combination of PD1 and CTLA4 antagonists could enhance the efficacy of checkpoint-based immunotherapics (78). Other tumor-infiltrating cells of myeloid lineage such as TANs, releasing excessive amounts of pro-tumor and pro-angiogenic cytokines/chemokines. Targeting these mediators, blocking immunosuppressive molecules expressed by tumor cells or tumor-infiltrating immune cells, and promoting anti-tumor immune responses, which can effectively treat a variety of tumors (9). Thus, TAMs and MDSCs affect the growth and metastasis of tumor cells and the efficacy of tumor immunotherapy through a variety of channels.

\section{Cell Metabolism and Other Tumor- Infiltrating Cells}

Cellular metabolism also has a critical important effect on the viability and function of both cancer cells and immune cells (79). Cancer cells up-regulate the absorption of nutrients and the production of waste metabolites, thus creating an immunosuppressive TME that allows it to escape and grow, and determines the fate of immune cells (80). Cell metabolism can be regulated using a combination of metabolic disruptors and immune checkpoint blockade (81). In addition to consuming key nutrients, tumors also produce large amounts of waste products such as lactic acid, arginine and tryptophan byproducts, and phosphoenolpyruvate, which can impair T-cell metabolism and function, then lead to a worse prognosis for patients (82). So cell metabolism becomes an attractive target for restoring anti-tumor immunity and developing anticancer therapies (81). Lactic acid is the primary cause of acidic PH and the inhibition of $\mathrm{pH}$-dependent $\mathrm{T}$ cell function in the tumor micro-environment. Lactic acid generated by tumors and acidification of the microenvironment improves the expression of ARG1 in TAMs, which is characteristic of the M2-assisted phenotype (83). The inhibition of the production of lactic acid in cancer cells helps to 
recover active oxygen homeostasis of physiological mitochondrial and restore normal function of cells (84). Therefore, the recovery of the anticancer immune response can be achieved by targeting inhibition of the lactic acid production pathway (85).

To sum up, it is strongly demonstrated that TME plays a critical role in tumor immunotherapy. But solutions to these two problems is that overcome the inherent immunosuppressive tumor environment and stimulate a strong adaptive response (8).

\section{THE EFFECT OF GUT MICROBIOTA AND ITS METABOLITES ON THE HOST IMMUNE SYSTEM AFFECTS TME SHAPING}

Gut microbiota plays fundamental roles in the development in the function, maintenance and development of the host immune system $(86,87)$. In the early stage of life, gut microbiota shapes the immune system, and the changes of gut microbiota will affect many aspects of the immune system in the later stage of life (88). Otherwise, the diversity of gut microbiota is crucial for the establishment of immune regulation networks (89). Generally, multiple gut microbiota establishes a symbiotic relationship with the host immune system and promotes the host homeostasis, the perturbation of this relationship will result in chronic inflammatory and autoimmune immunopathology, thereby may causing or aggravating the formation and development of cancer (90). TME is the environment in which tumors grow, it can regulate tumor growth, promote tumor invasion and metastasis, mediate tumor immune escape, and promote or weaken the carcinogenic process $(86,91)$. The crosstalk between gut microbiomes and microbiome metabolites in TME is continuous and beneficial, that affects the TME by affecting host immunity and intestinal epithelium, and promotes or inhibits the development of tumor (Figure 2) (53, 92). For example, the efficacy of conventional chemotherapy and immunotherapy for pancreatic cancer are affected by the involvement of gut microbiota in the metabolism of TME (93). Based on the close interaction between host microbiota and immune response in TME, it is suggested that manipulating gut microbiota is a feasible strategy for anticancer therapy (94).

\section{Interaction Between Gut Microbiota and Microbiome Metabolites With Host Immunity Affects TME}

Normal or pathological immune response will occur in the tumor treatment (95). Gut microbiota modulates the whole host immune, which impacts the distant preneoplastic lesions toward malignancy or regression. The interaction between gut microbiota and host immune enhances the possibility that the TME interacts with broader systemic microbial-immune networks, that reminds that the gut microbiota is emerging as an essential modulator of TME (96-100).

It is known that among immune cells, neutrophils and Treg as key cells in cancer development and growth (98, 101-103). Neutrophils can activate the interaction between cancer cells and endothelial cells in the primary TME, thus promoting tumor metastasis. In melanoma, neutrophils recruited by Toll-like receptor 4 (TLR4) signal can induce cancer cells to migrate to

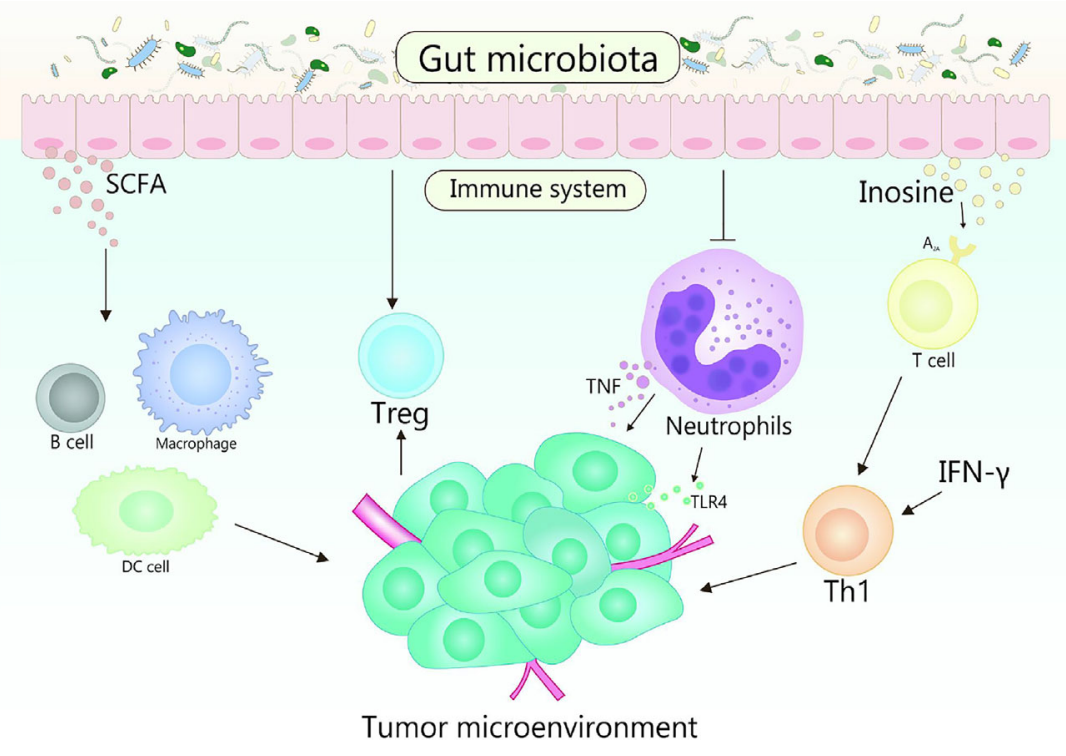

FIGURE 2 Gut microbiota and its metabolites act on the host immune system to influence the shaping of the TME. TLR4 signaling in tumor cells is able to recruit neutrophils, while TNF released by neutrophils is able to induce metastasis of tumor cells. Gut microbiota is beneficial to reduce the number of neutrophils, which plays a promoting role in the treatment of tumors. Gut microbiota metabolite inosine significantly promotes the differentiation of Th1 cells in the presence of exogenous interferon- $\gamma$ by acting on the A2A receptor on T cells, while SCFA can regulate the production of cytokines, affect the class conversion of B cells, activate DC cells and macrophages, and affect the differentiation of memory $T$ cells, which also plays an important role in cancer therapy. 
endothelial cells through tumor necrosis factor (TNF), resulting in enhancing cancer metastasis (104). Meanwhile, the adhesion of cancer cells is mediated by neutrophil Mac-1/ICAM-1, thus affecting its metastasis (1). Moreover, cytokines, chemokines, growth factors, and serine proteases of neutrophils shape microenvironment that contribute to the tumor growth (102). Cytokines released by tumor and TME send out an emergency signal to stimulate a large number of neutrophils to enter the blood circulation and accelerate the metastasis of cancer cells (105). However, the number of neutrophils in circulation is reduced by abundant gut microbiota. One research found the mice applying with L.reuteri showed a better capacity of wound healing, which is achieved by reducing the number of neutrophils in circulation through the increase of Foxp3 and Tregs (106). Another research pointed out the same result that the cachexia mice treated with L.reuteri showed decreased systemic inflammation and better tumor inhibition, which also associated with the reduction of neutrophils in the blood (107). And, the neutrophil homeostasis will be affected by microbiota through enterocyte CXCL5-mediated signaling and IL-17 (108).

Treg is essential for maintaining the homeostasis of the immune system and the balance of beneficial inflammatory response during infection (109). Treg regulates the host immune response which gathers near TME, suppresses the anti-tumor inflammatory response and counteracts antigenspecific effector T-cell responses, consequently (109-111). The differentiation and proliferation of Treg, and the secretion and recruitment of immunosuppressive factors will be activated by TME, then contribute to the immunosuppression of tumor tissue (112). Based on the data of animal models, it has been found that the Treg induced by some specific gut microbiota could change the TME, which is beneficial to relieve the induction of cancer. For example, $\mathrm{CD}^{+} \mathrm{CD} 25^{+}$Treg cells inhibit the occurrence of colon cancer by inhibiting the development of $H$. hepaticusinduced inflammation and dysplasia (113), the effectiveness of Treg cells will be enhanced by the infection from gut pathogens, thereby inhibiting the occurrence of breast cancer (114). Gut microbiota response mediated by IL $22^{+}$innate lymphoid cells, Th17 cells and Treg cells occurred in mice lacking adaptive immunity, indicating that gut microbiota can promote the innate immunity (115). The mechanism of tumor reduction driven by microbiota may induce the anticancer immune response $(102,116)$.

Otherwise, the intestinal epithelial barrier, a physical barrier, that are extremely essential in maintaining the balance of the intestinal environment (117). On the one hand, the common gut microbiota can enhance immunoglobulin A production in the intestinal tract by regulating the response of B cells to maintain an intact epithelial barrier $(118,119)$, which also is a key figure in the development of the immune system $(92,120)$. Once this barrier is broken, the main inflammation-activating transcription factor $\mathrm{NF}-\kappa \mathrm{B}$ will be activated (121). The activation of $\mathrm{NF}-\mathrm{\kappa B}$ in ovarian cancer cells responds to inflammatory chemokines and cytokines in the TME, which helps to create an immune escape environment and attract infiltrating immune cells with tumor-promoting phenotypes (122). The origin of tumor-promoting inflammation is quite clear in gastrointestinal cancer, most of which can be attributed to the destruction of epithelial barrier integrity (123). On the other hand, intestinal epithelial cells can activate the NOTCH1 signal and lead to a high penetrating transfer of colorectal cancer (124).

Thus, the interaction between neutrophils and TME accelerates the progression of tumors, and the dynamic balance of neutrophils is affected by gut microbiota. Treg gathers near TME with an immunosuppressive effect, which is induced by specific gut microbiota to changes TME, thereby alleviate cancer. Maintaining the integrity of the intestinal epithelium can be maintained by gut microbiota, which is conducive to reduce e the incidence of cancer.

\section{Interaction Between Gut Microbiota Metabolites and Host Immunity Affects TME}

Gut microbiota metabolites enter host cells and mutually interact thereby affecting the immune response and disease risk, promote a variety of tumor inhibitory and immunomodulatory effects, and inhibit inflammation by maintaining the integrity of epithelial barrier and intestinal tract $(9,125)$. Accumulating evidence suggests that gut microbiota metabolites and products of their metabolic activities influence important metabolic pathways of the host related to food intake, adiposity, lipid and energy homeostasis $(114,126-131)$.

Some fatty acids and cholic acids are related to inflammation. SCFAs contribute to maintaining intestinal homeostasis and regulating intestines' barrier function $(132,133)$. It acts on $G$ protein-coupled receptors (GPCRs) to inhibit the metastasis of breast cancer (134). Butyrate, an SCFAs, produced by Faecalibacterium prausnitzii, which has the ability to suppress angiogenesis and reduce the expression of pro-angiogenic factors, so increasing the concentration of butyrate can play a role in protecting and preventing cancer (135-137). In addition, Deoxycholic acid (DCA) and petrocholic acid (LCA) potentially cause DNA damage by enhancing the production of ROS (138). DNA damage causes cell senescence, chronic inflammation, and tumorigenesis (139). Recent studies have suggested that the metabolite inosine was produced by intestinal bacteria $B$. pseudolongum, which significantly promoted Th1 cell differentiation in the presence of exogenous IFN- $\gamma$ and enhanced the therapeutic response of ICB therapy including anti-CTLA-4 and anti-PD-L1, by acting on adenosine $A_{2 A}$ receptor on $\mathrm{T}$ cells (12). Understanding how the metabolites and sub-metabolites of gut microbiota affect immune cell subsets and their actions to reshape TME may be the direction of future research.

Specific gut microbiota interacts with immune cells to promote tumor clearance, slow metastasis of cancer cells and inhibit chronic inflammation, thus mitigating against cancer. The gut microbiota metabolites, such as SCFAs and inosine, directly or indirectly interact with TME to reshape TME, and 
affect the cancer process. However, a study has found that some gut microbiota (such as Bacteroides and Ruminococcaceae) can participate in the occurrence of HCC by aggravating hepatocyte inflammation, accumulating toxic compounds and leading to liver steatosis (23). Therefore, a comprehensive understanding of the interaction mechanism between gut microbiota and its metabolites with the host immune system in reshaping and regulating TME through gut microbiota is profound for cancer immunotherapy.

\section{THE EFFECT OF GUT MICROBIOTA IN CANCER IMMUNOTHERAPY}

Immunotherapy realizes the result of eliminating tumors by suppressing negative immune regulatory factors, activating the immune system and enhancing the recognition, thereby killing of immune cells to tumors (140). With further research, it has been verified that the gut microbiota could regulate the immune response, thus affect the effectiveness of cancer immunotherapy $(120,141)$. Various mechanisms mediated by gut microbiota affect the therapeutic response and toxicity of immune checkpoint inhibitors (ICIs), chemotherapy, and stem cell transplant (Figure 3) (142). In fact, some studies indicate that there is a strong correlation between gut microbiota and immune checkpoint response (143-145). Gut microorganisms play a crucial role in cancer treatment by eliminating anticancer effects and mediating toxicity.

\section{Anti-CD47 Therapy}

Tumor immunotherapy identified and kills tumor cells through the host immune system, and more and more attention has been paid to the research in this field (146-148). CD47, as a signal molecule to help tumor cells escape, conveys the "don't eat me" signal to immune cells and produces a good effect of tumor immunotherapy by blocking the CD47 $(149,150)$. CD47 is a kind of transmembrane protein that has interactions with signal regulatory protein (SIRP) expressed on macrophages and DCs (151). It is a hint of a poor prognosis when CD47 can highly express in malignant tumors, for example, leukemia, myeloma, ovarian tumor, and so on $(152,153)$.

Anti-CD47 antibody therapy makes not only cancer cells swallowed by macrophages but also anti-tumor cytotoxic $\mathrm{T}$ cell immune response initiated (154). Researches have shown that $\mathrm{CD}^{+} \mathrm{T}$ cells are essential for anti-CD47-mediated tumor regression, and tumor-resident DCs can enhance anti-CD47 by cross-stimulation of antigen-specific T cells (150). In addition, DC-specific type I IFN plays a critical role in enhancing the adaptive immune response to anti-CD47 antibody therapy (149, 150). A research pointed out that the main anti-tumor effect of anti-CD47 monoclonal antibodies is attributed to the activation of host cGAS-STING pathway mediated by mitochondrial DNA in DC (150).

Anaerobes play a dominant role in the gastrointestinal tract, among common anaerobes, Bifidobacterium is a functional gut microbiota, which is widely used in the treatment of inflammatory gastrointestinal diseases such as ulcerative colitis $(155,156)$. TME in a low oxygen state creates a good growth

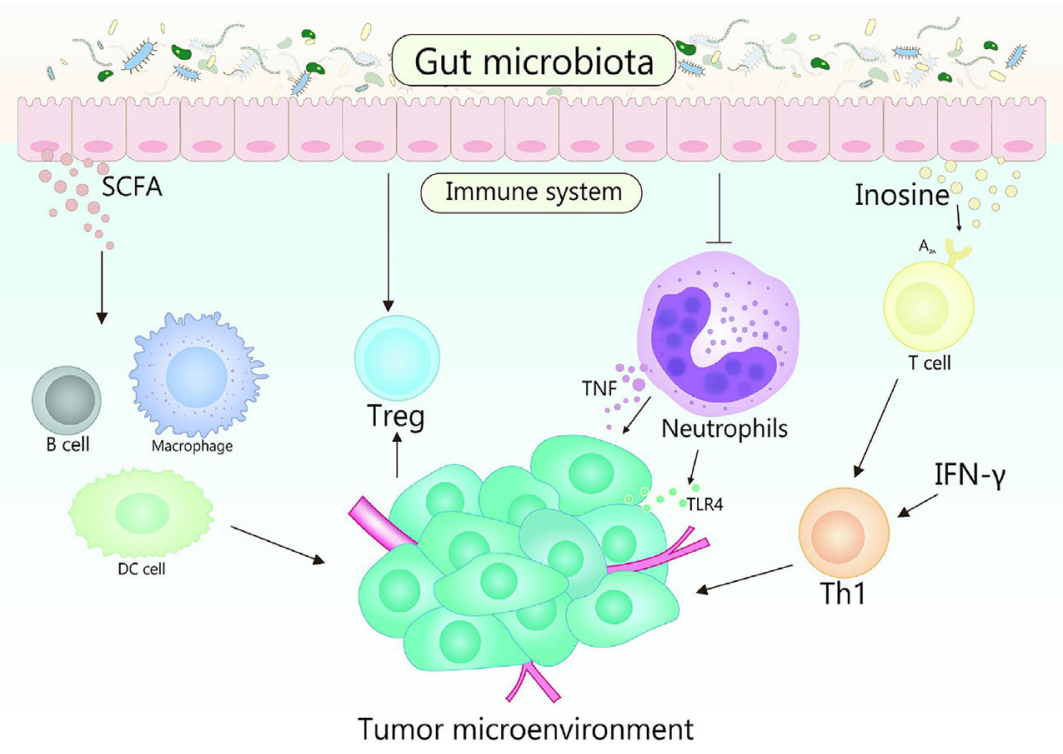

FIGURE 3 | Role of gut microbiota in cancer immunotherapy. Gut microbes can stimulate the body to produce CD47 antibodies by activating STING signaling, thereby promoting immunotherapy. It is reported that the cross-priming of antigen-specific T cells of tumor-resident DCs can be enhanced by anti-CD47 therapy. In addition, type I IFN plays an important role in enhancing the adaptive immune response to anti-CD47 antibody therapy in tumor-resident DCs. Accumulation of Bifidobacteria in the TME can significantly improve the antitumor efficacy of anti-CD47 immunotherapy, which is dependent on STING signaling and type I IFN within DCs. Bifidobacteria may affect activating DC cells, thereby improving the activity of tumor-specific CD8 ${ }^{+} \mathrm{T}$ cells. The key role of B. fragilis is to restore the anti-CTLA4 treatment response associated with Th1 immune responses in tumor-draining lymph nodes. 
environment for anaerobic bacteria (157). A study indicated that the accumulation of Bifidobacterium in TME can significantly improve the anti-tumor effect of anti-CD47 immunotherapy, which depends on the STING signal and the type I IFN within DC (158). CD47 is widely expressed in a variety of solid human tumors. At present, the related mechanism of CD47 has been extensive and in-depth research. However, there are few studies on the influence of gut microbiota on anti-CD47 immunotherapy, which has a great prospect.

\section{Interaction Between Gut Microbiota and ICls}

Immune checkpoints are a type of membrane-bound molecules, which can impede uncontrolled $\mathrm{T}$-cell response after initial stimulation. This mechanism can be used for cancer cells to escape immune surveillance. ICIs, however, can reactivate the inefficient $\mathrm{T}$ cells and recover the response to tumor antigens (159). Based on the current research background, CTLA-4, PD-1, and PD-L1 are the most in-depth target of immune checkpoint therapy. CTLA-4, PD-1, or PD-L1 have shown strong antitumor activity in the experimental animal models and the long-lasting clinical efficacy in cancer patients, such as melanoma, renal cell cancer, and lung cancer (159). Clinical studies and preclinical trials have shown that the efficacy of ICIs is affected by gut microbiota, which explains the large individual differences in patients' responses to ICIs $(160,161)$. At present, a variety of inhibitions about them have been invented and used or used or tested in the clinic (Table 1). Obviously, the response of ICIs is closely decided by the diversity and composition of gut microbiota $(160,162)$.

PD-1 and PD-L1 are members of the immune checkpoint proteins relating to the suppression of the immune system and delivering inhibitory signals to T cells (163). Cancer immunotherapy targeting PD-L1 and PD-1 has been widely carried out, and gut microbiota has been proposed to affect its efficacy and toxicity. Maston et al. analysis of 38 fecal samples from patients with metastatic melanoma who received anti-PD1 therapy, it is found that Bifidobacterium longum, Enterococcus faecalis, and Collinsella aerofaciens contribute to a better prognosis (145). Researchers transferred the fecal material from Jackson Laboratory (JAX) or Taconic Farms (TAC) from one mouse to another by oral gavage before tumor implantation and pointed out that the DCs may be activated by the increasing abundance of Bifidobacterium longum, thus improve tumor-specific $\mathrm{CD}^{+} \mathrm{T}$ cells activity (160). With researches obtain more attention to identifying the specific bacteria genres that play a critical role in human immunity by clinical experiments. Gopalakrishnan et al. found the melanoma patient respond to anti-PD1 treatment has higher microbial diversity, including the abundance of Ruminococcaceae, Clostridiales, and Faecalibacterium, patients with more Faecalibacterium has a significantly prolonged progression-free survival with a higher level of effector $\mathrm{T}$ cells and a stabilized cytokine response to PD-1 blockade, simultaneously, systemic and anti-tumor immunity are also enhanced (144). Another research also achieved the same opinions, they found the Alistipes putredinis, Bifidobacterium longum, and Prevotella copri were enriched in responsive patients with advanced non-small-cell lung carcinoma who were being treated with PD-1 blockade therapies, expectedly, a greater frequency of memory $\mathrm{CD}^{+} \mathrm{T}$ cell and $\mathrm{NK}$ cell subgroups was observed in the periphery blood of responding patients (164). The abundance of the gut microbial flora acting as immune adjuvants in the immunotherapy of PD-1 and the T cell response may deeply connect with the PD-1/PD-L1 immunotherapy, and relevant researches have shown that the patients with endogenous $\mathrm{T}$ cell response in TME are more effective in immunotherapy $(165,166)$. The hot tumor with a large number of $\mathrm{T}$ cell infiltration, which has the highest response rate to tumor immunotherapy (167). Targeted inhibition of Vps34, can transform "cold tumor" into "hot tumor", thus enhancing the efficacy of PD-L1/PD-1 blocking therapy (168).

TABLE 1 | Modulatory function of gut microbiome in ICls therapy.

\begin{tabular}{|c|c|c|c|}
\hline Bacteria & Model & Modulatory function of gut microbiome in ICls therapy & References \\
\hline Bifidobacterium adolescentis & Mouse & $\begin{array}{l}\text { (1) Stimulating DCs directly, inducing DCs maturation and cytokine secretion } \\
\text { (2) Anti-tumor function and synergistic effect with PD-1 blockade }\end{array}$ & $(160)$ \\
\hline Bacteroides fragilis & Mouse & $\begin{array}{l}\text { (1) Immunostimulation induced by CTLA-4 blockade } \\
\text { (2) Promoting the maturation of DCs in tumor cells and inducing Th1 cell activation }\end{array}$ & $(161)$ \\
\hline Bacteroides thetaiotaomicron & Mouse & $\begin{array}{l}\text { (1) Anti-tumor effect of CTLA-4 blockade } \\
\text { (2) Promoting Th1 immune response }\end{array}$ & $(161)$ \\
\hline Blautia obeum & Human & Related to impaired efficacy of PD-1 blockers & $(103)$ \\
\hline Collinsella aerofaciens & Human & $\begin{array}{l}\text { (1) Results in decreased peripheral blood Treg } \\
\text { (2) Associated with enhanced efficacy of PD-1 blockade }\end{array}$ & (103) \\
\hline Enterococcus faecium & Human & $\begin{array}{l}\text { (1) Results in decreased peripheral blood Treg } \\
\text { (2) Associated with enhanced efficacy of PD-1 blockade }\end{array}$ & $(103)$ \\
\hline Klebsiella pneumonia & Human & (1) Associated with enhanced efficacy of PD-1 blockade & $(103)$ \\
\hline Parabacteroides merdae & Human & $\begin{array}{l}\text { (1) Results in decreased peripheral blood Treg } \\
\text { (2) Associated with enhanced efficacy of PD-1 blockade }\end{array}$ & (103) \\
\hline Roseburia intestinalis & Human & Related to impaired efficacy of PD-1 blockers & $(103)$ \\
\hline Veillonella parvula & Human & Associated with enhanced efficacy of PD-1 blockade & $(103)$ \\
\hline Ruminococcaceae & Human/mouse & $\begin{array}{l}\text { (1) Associated with enhanced efficacy of PD-1 blockade } \\
\text { (2) Increasing effector T cell levels in peripheral blood and TILs }\end{array}$ & $(11)$ \\
\hline Enterococcus hirae & Human/mouse & $\begin{array}{l}\text { (1) Synergistic effect with PD-1 blockers in combination with Ackerman mucilaginosa } \\
\text { (2) Improving traditional Chinese medicine combined with Ackerella Sinensis }\end{array}$ & $(12)$ \\
\hline Alistipes indistinctus & Human/mouse & Restoring the anti-tumor efficacy of PD-1 blockers & $(12)$ \\
\hline
\end{tabular}


CTLA-4, also known as CD152, is constitutively expressed in Tregs and acts as an immune checkpoint that decreases immune responses (169). Vetizou et al. found that a key role of Bacteroides thetaiotaomicron or Bacteroides fragilis restores response to the anti-CTLA-4 therapy associated with Thelper 1 immune responses in tumor-draining lymph nodes and maturation of intratumoral DCs, activation of effector CD4+ $\mathrm{T}$ cells and TILs elicited by CTLA-4 blockade was considerably dampened in germ-free or antibiotics mice, otherwise, the intestinal reconstitution of antibiotic-treated mice with Bacteroides and Burkholderia genres could restore the CTLA-4 blockade-mediated anticancer responses (161). The abundance of Bacteroides in patients with new immunemediated colitis treated with anti-CTLA-4 was significantly lower than that in patients without colitis treated with ipilimumab. Meanwhile, the response of mice to anti-CTLA4 antibody could be restored and the degree of immune-mediated colitis could be significantly reduced by taken orally administration of Bacillus fragilis and Bacillus cepacia (170). However, a single dose of Bacillus fragilis or B.thaiotaomicron could not receive the same effect $(161,171)$. Vancomycin enhances the blocking effect of CTLA-4 by increasing the proportion of Gram-negative Burkholderia and Bacteroides in the intestines (161). It may prove that Bacillus can be used to regulate the efficacy of anti-CTLA-4 therapy.

Another research suggested that the special gut microbiota contributes to both CTLA4 and anti-PD-L1 immunotherapy. Three bacteria from the intestinal tract, Bifidobacterium pseudolongum, Lactobacillus johnsonii, and Olsenella from the intestinal tract significantly enhanced the efficacy of anti-CTLA4 and anti-PD-L1 immunotherapy in four different cancer mice when they were introduced into aseptic mice with ICIs, and the Bifidobacterium pseudolongum in the intestine contributes to regulating and enhancing the immunotherapeutic response by producing inosine (12). Based on these reports suggest that the commensal microbiome may have a mechanistic impact on antitumor immunity in cancer patients, and a growing number of studies have also emphasized that the gut microbiota could modulate response to cancer immunotherapy. Consequently, the further research about the effect and the potential mechanism of gut microbiota in ICIs is profound for cancer treatment. Innovative treatments were used to study and not widely applicate in patients, so it is necessary that further works must unlock the mystery of microbial modulation in various anticancer immunotherapies.

\section{Gut Microbiota Affect the Efficacy of Cancer Immunotherapy}

Abundant gut microbiota plays a regulatory role in tumor therapy, which has a critical role in regulating the efficacy and toxicity of cancer immunotherapy (172). The effect of gut microbiota on the efficacy and interaction of ICIS has been verified in melanoma, non-small cell lung cancer, urethral epithelial carcinoma, and renal cell carcinoma (144, 145,
173). Lukas F Mager et al. found that Bifidobacterium pseudolongum, Lactobacillus johnsonii, and Olsenella enhanced efficacy quadrupled of ICIs in four mouse models of cancer (12). It is suggested that selective regulation of gut microbial population may help to overcome the resistance to ICIs $(159,167)$.

Among radiotherapy, ionizing radiation therapy (RTX) is an effective method for tumors treatment, but severe oral mucositis and bowel disease caused by RTX may limit the completion of treatment, fortunately, the probiotics such as Lactobacillus casei, Rhamnose and Bifidobacterium have been shown to reduce radiotherapy-associated diarrhoea in mouse models by inhibiting the expression of TNF, IL1b, and IL6mRNA (174-176). It is reported that complete response of tumor cells with local temperature causing by infrared radiation of a specific wavelength, and the formation of the tumor specific thrombus can achieve effective photothermal immunotherapy of cancer through the action of attenuated Salmonella in an innovative photothermal therapy (177). On the other hand, gut microbiota may reduce the side effects of a variety of chemotherapy. In chemotherapy, cyclophosphamide (CTX), one of the most commonly used chemotherapeutic drugs in treating lymphomas and solid tumors, inducing immunogenic cancer cell death and immunomodulatory effects (178). Orally administrated with Enterococcus hirae cause a restoration of CTX anti-tumor efficacy by inducing differentiation of TH17 and pathogenic TH17 cells, promoting tumor-specific Th1 and CTL activity (179). Abiraterone acetate is both an inhibitor of androgen biosynthesis and a highly effective drug of prostate cancer, which reduces the harmful microorganisms and promotes the growth of anticancer microorganisms through metabolizing the gut microbiota (180). Otherwise, Pushalkar et al. suggested that bacterial ablation can reshape TME in the orthotopic mouse model of pancreatic cancer (PDAC), induce activation of $\mathrm{T}$ cell and increase the sensitivity of immunotherapy (181).

Excepting the related advantages, the correlation between the composition of intestinal microbial community and the degree of TNF shows that some Lactobacillus strains, such as fermented Lactobacillus, are considered as weakening the response to immunotherapy (182). The composition of gut microbiota is related to the different development of graftversus-host disease (GVHD). It has high morbidity and mortality, when the cross reaction occurs between the donor cells (usually $\mathrm{T}$ cells) the graft and the patient's major histocompatibility. On the contrary, it was found that increased bacterial diversity and increased amounts of Blautia to be related to reduce GVHD mortality and improve survival (183).

At present, research has moved away from the approach based on association toward mechanism as the advances in sequencing technology and the development of powerful computing tools. Elucidating the relationship between the gut microbiome and cancer as well as the potential mechanism has become the priorities of further research, which also the main method for cancer immunotherapy. 


\section{CONCLUSION AND FUTURE PERSPECTIVE}

The gut microbiota activates the host immune system further and has an anti-cancer effect, and more superiority than the traditional way of treating cancer. In addition, the interaction between gut microbiota and cancer ICIs play an antitumor immune therapy, this way of targeted therapy in cancer immunotherapy is getting more and more recognition. Targeting and manipulating cells and factors in TME during cancer therapy, which contribute to control malignancies and obtain positive health outcomes (132). An in-depth understanding of TME, its role and related molecules will provide important insights into the biological behavior of different tumor types. Molecules and tumorigenic processes in TME are considered as the key targets of the new therapy strategy of cancer $(86,184)$. The refining of molecular cells and immune regulation of therapeutic targets is increasing in the TME, and the clinical application also is growing more and more widely, for example, that resistance to $\mathrm{PD}-1 / \mathrm{PD}-\mathrm{L} 1$ plays multiple roles in tumor immunotherapy, however, the test of limited activity PD-1 of resisting tumor types may have a good therapeutic effect in the strategy of reshaping the tumor inert environment in the future. Namely the possibility of immunotoxicity and immunotherapy to enhance antitumor immunity, in other words, use reasonable and selective combined immunotherapy in a limited TME to reactivate the anti-tumor immune response (185).

In the previous introduction, we have known that gut microbiota is essential in maintaining the host balance, promoting physiological responses including the protection of pathogen, host metabolism, host immunity response, and so on. More and more scientific evidence showed that broken the delicate balance of gut microbiota can lead to the occurrence of cancer and other diseases, which indicates that modulating strategy is very important. In fact, gut microbiota has great interindividual heterogeneity due to the impact of host, including the age, living environment, genetic factor, and diet habit. Among them, diet habit and host age are the main determinants of gut microbiota according to the biological relationship between gut microbiota and host in nutrient digestion (186). It is reported that the diversity of gut microbiota and its metabolites were changed by diet habit (187). The overall richness of gut microbiota decreases with age, and some microbial taxa related to unhealthy aging appear, which leads to the malnutrition of gut microbiota, then finally affect the host's innate immune response (188). Fecal microbiota transplant (FMT), live biotherapeutics, diet habits, and prebiotics are the main strategies to regulate gut microbiota, making it more healthy (189). For example, patients with colon cancer have obvious characteristics and diversity of gut microbiota in tumor tissue and nearby mucosa. After taking probiotics, the abundance of butyrate-producing bacteria in tumors, non-tumor mucosa, and fecal flora increased in these patients, that helps maintain the intact intestinal barrier to avoid the activation of inflammation-related factors in $\operatorname{TME}(190,191)$. The report pointed out that non-responders lack beneficial bacteria which are critical to the anti-tumor effect of immunotherapy, however, the effect of them on ICIS can be restored by transplanting these bacteria from responders to nonresponders by some means, such as FMT, probiotic therapy, and so on (192).

In addition, determining the composition of individual gut microbiota is also a way to solve the huge heterogeneity among individuals in the gut microbiota. Searching for microbial signals to determine the degree of response to cancer treatment may help determine gut microbiota composition associated with specific treatment categories or overlapping signals, which is suitable for a wide range of immune therapy. But the microbe signal is a continuous work, the differences of sequencing technology and patient cohort were all factors that affect microbial expression (193). The composition of gut microbiota havs undergone a similar change during cancer progression and treatment, and this change causes more additional challenges. Cancer cells grow and evolve under the therapy of selective pressure. Molecular evolution of tumors may still occur when gut microbiota is manipulated to maximize immunotherapeutic efficacy. Therefore, future research may be able to use DNA sequencing, metabolomics technologies and high-dimensional data, as well as to give them intervention, the interdependence of individual host-intestinal microflora can provide more effective treatment and greatly promote the development of microbial alliance to treat specific disease (194). More challenges need to be overcome by combination with basic experimental and clinical research. Therefore, we look forward to getting more precise therapies targeted cancer coming from gut microbiota and the TME in the future. It is also suggested that further studies should focus on the precise targets and mechanisms of action in this field.

\section{AUTHOR CONTRIBUTIONS}

$\mathrm{LL}$ and $\mathrm{RH}$ conceived and designed the review. QQ, YM, YL, ZC, JL, XL, and LL wrote the manuscript. LL, YH, and HL reviewed the paper and provided comments. All authors contributed to the article and approved the submitted version.

\section{FUNDING}

This project was supported by the Ph.D. Start-up Fund of Guangdong Medical University (B2019016); Administration of Traditional Chinese Medicine of Guangdong Province (20201180); Science and Technology Special Project of Zhanjiang (2019A01009); Natural Science Foundation of Guangdong Province (2016B030309002); Basic and Applied Basic Research Program of Guangdong Province (2019A1515110201); GDNRC[2020]038; Educational Commission of Guangdong Province (4SG20138G); and Fund of Southern Marine Science and Engineering Guangdong Laboratory (Zhanjiang) (ZJW-2019-007). 


\section{REFERENCES}

1. Arneth B. Tumor Microenvironment. Medicina (Kaunas Lithuania) (2019) 56(1):15. doi: 10.3390/medicina56010015

2. Casey SC, Amedei A, Aquilano K, Azmi AS, Benencia F, Bhakta D, et al. Cancer prevention and therapy through the modulation of the tumor microenvironment. Semin Cancer Biol (2015) 35Suppl(Suppl):S199-s223. doi: 10.1016/j.semcancer.2015.02.007

3. Janji B, Berchem G, Chouaib S. Targeting Autophagy in the Tumor Microenvironment: New Challenges and Opportunities for Regulating Tumor Immunity. Front Immunol (2018) 9:887. doi: 10.3389/fimmu.2018.00887

4. Binnewies M, Roberts EW, Kersten K, Chan V, Fearon DF, Merad M, et al. Understanding the tumor immune microenvironment (TIME) for effective therapy. Nat Med (2018) 24(5):541-50. doi: 10.1038/s41591-018-0014-x

5. Jiao S, Subudhi SK, Aparicio A, Ge Z, Guan B, Miura Y, et al. Differences in tumor microenvironment dictate $\mathrm{T}$ helper lineage polarization and response to immune checkpoint therapy. Cell (2019) 179(5):1177-90.e13. doi: 10.1016/j.cell.2019.10.029

6. Vinay DS, Ryan EP, Pawelec G, Talib WH, Stagg J, Elkord E, et al. Immune evasion in cancer: Mechanistic basis and therapeutic strategies. Semin Cancer Biol (2015) 35(Suppl):S185-s98. doi: 10.1016/j.semcancer.2015.03.004

7. Poutahidis T, Erdman SE. Commensal bacteria modulate the tumor microenvironment. Cancer Lett (2016) 380(1):356-8. doi: 10.1016/ j.canlet.2015.12.028

8. Zhang Y, Yu G, Chu H, Wang X, Xiong L, Cai G, et al. Macrophageassociated PGK1 phosphorylation promotes aerobic glycolysis and tumorigenesis. Mol Cell (2018) 71(2):201-15.e7. doi: 10.1016/ j.molcel.2018.06.023

9. Zhou Y, Fei M, Zhang G, Liang WC, Lin W, Wu Y, et al. Blockade of the Phagocytic Receptor MerTK on Tumor-Associated Macrophages Enhances P2X7R-Dependent STING Activation by Tumor-Derived cGAMP. Immunity (2020) 52(2):357-73.e9. doi: 10.1016/j.immuni.2020.01.014

10. Böttcher JP, Bonavita E, Chakravarty P, Blees H, Cabeza-Cabrerizo M, Sammicheli S, et al. NK cells stimulate recruitment of $\mathrm{cDC1}$ into the tumor microenvironment promoting cancer immune control. Cell (2018) 172 (5):1022-37. e14. doi: 10.1016/j.cell.2018.01.004

11. Erdman SE, Poutahidis T. The microbiome modulates the tumor macroenvironment. Oncoimmunology (2014) 3:e28271. doi: 10.4161/ onci.28271

12. Mager LF, Burkhard R, Pett N, Cooke NC, Brown K, Ramay H, et al. Microbiome-derived inosine modulates response to checkpoint inhibitor immunotherapy. Science (2020) 369(6510):1481-9. doi: 10.1126/ science.abc3421

13. Yang W, Yu T, Huang X, Bilotta AJ, Xu L, Lu Y, et al. Intestinal microbiotaderived short-chain fatty acids regulation of immune cell IL-22 production and gut immunity. Nat Commun (2020) 11(1):4457. doi: 10.1038/s41467020-18262-6

14. Ohtani N. Microbiome and cancer. Semin Immunopathol (2015) 37(1):6572. doi: 10.1007/s00281-014-0457-1

15. Dibra D, Xia X, Mitra A, Cutrera JJ, Lozano G, Li S. Mutant p53 in concert with an interleukin-27 receptor alpha deficiency causes spontaneous liver inflammation, fibrosis, and steatosis in mice. Hepatology (Baltimore $M d$ ) (2016) 63(3):1000-12. doi: 10.1002/hep.28379

16. Ben-Shmuel A, Biber G, Barda-Saad M. Unleashing Natural Killer Cells in the Tumor Microenvironment-The Next Generation of Immunotherapy? Front Immunol (2020) 11:275. doi: 10.3389/fimmu.2020.00275

17. Wu J, Chen J, Feng Y, Tian H, Chen X. Tumor microenvironment as the "regulator" and "target" for gene therapy. J Gene Med (2019) 21(7):e3088. doi: 10.1002/jgm.3088

18. Vito A, El-Sayes N, Mossman K. Hypoxia-Driven Immune Escape in the Tumor Microenvironment. Cells (2020) 9(4):992. doi: 10.3390/cells 9040992

19. Wang T, Green R, Howell M, Martinez T, Dutta R, Mohapatra S, et al. The design and characterization of a gravitational microfluidic platform for drug sensitivity assay in colorectal perfused tumoroid cultures. Nanomedicine (2020) 30:102294. doi: 10.1016/j.nano.2020.102294

20. Quail DF, Joyce JA. Microenvironmental regulation of tumor progression and metastasis. Nat Med (2013) 19(11):1423-37. doi: 10.1038/nm.3394
21. Wan S, Kuo N, Kryczek I, Zou W, Welling TH. Myeloid cells in hepatocellular carcinoma. Hepatology (2015) 62(4):1304-12. doi: 10.1002/ hep. 27867

22. Yang L, Zhang Y. Tumor-associated macrophages: from basic research to clinical application. J Hematol Oncol (2017) 10(1):58. doi: 10.1186/s13045017-0430-2

23. Ponziani FR, Nicoletti A, Gasbarrini A, Pompili M. Diagnostic and therapeutic potential of the gut microbiota in patients with early hepatocellular carcinoma. Ther Adv Med Oncol (2019) 11:1758835919848184. doi: 10.1177/ 1758835919848184

24. Li Z, Li N, Li F, Zhou Z, Sang J, Chen Y, et al. Immune checkpoint proteins PD-1 and TIM-3 are both highly expressed in liver tissues and correlate with their gene polymorphisms in patients with HBV-related hepatocellular carcinoma. Medicine (Baltimore) (2016) 95(52):e5749. doi: 10.1097/ md.0000000000005749

25. Cho H, Kang H, Lee HH, Kim CW. Programmed Cell Death 1 (PD-1) and Cytotoxic T Lymphocyte-Associated Antigen 4 (CTLA-4) in Viral Hepatitis. Int J Mol Sci (2017) 18(7):1517. doi: 10.3390/ijms18071517

26. Wang T, Shen Y, Luyten S, Yang Y, Jiang X. Tissue-resident memory CD8 (+) T cells in cancer immunology and immunotherapy. Pharmacol Res (2020) 159:104876. doi: 10.1016/j.phrs.2020.104876

27. Corgnac S, Boutet M, Kfoury M, Naltet C, Mami-Chouaib F. The Emerging Role of CD8(+) Tissue Resident Memory T (T(RM)) Cells in Antitumor Immunity: A Unique Functional Contribution of the CD103 Integrin. Front Immunol (2018) 9:1904. doi: 10.3389/fimmu.2018.01904

28. Mami-Chouaib F, Blanc C, Corgnac S, Hans S, Malenica I, Granier C, et al. Resident memory $\mathrm{T}$ cells, critical components in tumor immunology. J Immunother Cancer (2018) 6(1):87. doi: 10.1186/s40425-018-0399-6

29. Blanc C, Hans S, Tran T, Granier C, Saldman A, Anson M, et al. Targeting Resident Memory $\mathrm{T}$ Cells for Cancer Immunotherapy. Front Immunol (2018) 9:1722. doi: 10.3389/fimmu.2018.01722

30. Fu C, Jiang A. Dendritic Cells and CD8 T Cell Immunity in Tumor Microenvironment. Front Immunol (2018) 9:3059. doi: 10.3389/fimmu. 2018.03059

31. Banchereau J, Steinman RM. Dendritic cells and the control of immunity. Nature (1998) 392(6673):245-52. doi: 10.1038/32588

32. Ma Y, Shurin GV, Peiyuan Z, Shurin MR. Dendritic cells in the cancer microenvironment. J Cancer (2013) 4(1):36-44. doi: 10.7150/jca.5046

33. Guilliams M, Ginhoux F, Jakubzick C, Naik SH, Onai N, Schraml BU, et al Dendritic cells, monocytes and macrophages: a unified nomenclature based on ontogeny. Nat Rev Immunol (2014) 14(8):571-8. doi: 10.1038/nri3712

34. Spranger S, Dai D, Horton B, Gajewski TF. Tumor-Residing Batf3 Dendritic Cells Are Required for Effector T Cell Trafficking and Adoptive T Cell Therapy. Cancer Cell (2017) 31(5):711-23.e4. doi: 10.1016/j.ccell. 2017.04.003

35. Broz ML, Binnewies M, Boldajipour B, Nelson AE, Pollack JL, Erle DJ, et al. Dissecting the tumor myeloid compartment reveals rare activating antigenpresenting cells critical for T cell immunity. Cancer Cell (2014) 26(5):63852. doi: 10.1016/j.ccell.2014.09.007

36. Salmon H, Idoyaga J, Rahman A, Leboeuf M, Remark R, Jordan S, et al. Expansion and Activation of CD103(+) Dendritic Cell Progenitors at the Tumor Site Enhances Tumor Responses to Therapeutic PD-L1 and BRAF Inhibition. Immunity (2016) 44(4):924-38. doi: 10.1016/j.immuni. 2016.03.012

37. Ruffell B, Chang-Strachan D, Chan V, Rosenbusch A, Ho CM, Pryer N, et al. Macrophage IL-10 blocks CD8+ T cell-dependent responses to chemotherapy by suppressing IL-12 expression in intratumoral dendritic cells. Cancer Cell (2014) 26(5):623-37. doi: 10.1016/j.ccell.2014.09.006

38. Dorner BG, Dorner MB, Zhou X, Opitz C, Mora A, Güttler S, et al. Selective expression of the chemokine receptor XCR1 on cross-presenting dendritic cells determines cooperation with CD8+ T cells. Immunity (2009) 31 (5):823-33. doi: 10.1016/j.immuni.2009.08.027

39. McColl SR. Chemokines and dendritic cells: a crucial alliance. Immunol Cell Biol (2002) 80(5):489-96. doi: 10.1046/j.1440-1711.2002.01113.x

40. Kennedy R, Celis E. Multiple roles for CD4+ T cells in anti-tumor immune responses. Immunol Rev (2008) 222:129-44. doi: 10.1111/j.1600065X.2008.00616.x 
41. Kitano M, Yamazaki C, Takumi A, Ikeno T, Hemmi H, Takahashi N, et al. Imaging of the cross-presenting dendritic cell subsets in the skin-draining lymph node. Proc Natl Acad Sci U S A (2016) 113(4):1044-9. doi: 10.1073/ pnas. 1513607113

42. Myers JA, Miller JS. Exploring the NK cell platform for cancer immunotherapy. Nat Rev Clin Oncol (2020) 1-16. doi: 10.1038/s41571020-0426-7

43. Zhang Q, Bi J, Zheng X, Chen Y, Wang H, Wu W, et al. Blockade of the checkpoint receptor TIGIT prevents NK cell exhaustion and elicits potent anti-tumor immunity. Nat Immunol (2018) 19(7):723-32. doi: 10.1038/ s41590-018-0132-0

44. Zhang C, Liu Y. Targeting NK Cell Checkpoint Receptors or Molecules for Cancer Immunotherapy. Front Immunol (2020) 11:1295. doi: 10.3389/ fimmu.2020.01295

45. Fang L, Gong J, Wang Y, Liu R, Li Z, Wang Z, et al. MICA/B expression is inhibited by unfolded protein response and associated with poor prognosis in human hepatocellular carcinoma. J Exp Clin Cancer Res (2014) 33(1):76. doi: 10.1186/s13046-014-0076-7

46. Zamai L, Ahmad M, Bennett IM, Azzoni L, Alnemri ES, Perussia B. Natural killer (NK) cell-mediated cytotoxicity: differential use of TRAIL and Fas ligand by immature and mature primary human NK cells. J Exp Med (1998) 188(12):2375-80. doi: 10.1084/jem.188.12.2375

47. Pesce S, Greppi M, Tabellini G, Rampinelli F, Parolini S, Olive D, et al. Identification of a subset of human natural killer cells expressing high levels of programmed death 1: A phenotypic and functional characterization. J Allergy Clin Immunol (2017) 139(1):335-46.e3. doi: 10.1016/ j.jaci.2016.04.025

48. Liu Y, Cheng Y, Xu Y, Wang Z, Du X, Li C, et al. Increased expression of programmed cell death protein 1 on NK cells inhibits NK-cell-mediated anti-tumor function and indicates poor prognosis in digestive cancers. Oncogene (2017) 36(44):6143-53. doi: 10.1038/onc.2017.209

49. Hsu J, Hodgins JJ, Marathe M, Nicolai CJ, Bourgeois-Daigneault MC, Trevino TN, et al. Contribution of NK cells to immunotherapy mediated by PD-1/PD-L1 blockade. J Clin Invest (2018) 128(10):4654-68. doi: $10.1172 /$ jci99317

50. Oyer JL, Gitto SB, Altomare DA, Copik AJ. PD-L1 blockade enhances antitumor efficacy of NK cells. Oncoimmunology (2018) 7(11):e1509819. doi: $10.1080 / 2162402 x .2018 .1509819$

51. Jiang T, Zhou C, Ren S. Role of IL-2 in cancer immunotherapy. Oncoimmunology (2016) 5(6):el163462. doi: 10.1080/2162402x.2016.1163462

52. Parihar R, Dierksheide J, Hu Y, Carson WE. IL-12 enhances the natural killer cell cytokine response to Ab-coated tumor cells. J Clin Invest (2002) 110 (7):983-92. doi: 10.1172/jci15950

53. Barry KC, Hsu J, Broz ML, Cueto FJ, Binnewies M, Combes AJ, et al. A natural killer-dendritic cell axis defines checkpoint therapy-responsive tumor microenvironments. Nat Med (2018) 24(8):1178-91. doi: 10.1038/ s41591-018-0085-8

54. Muntasell A, Ochoa MC, Cordeiro L, Berraondo P, López-Díaz de Cerio A, Cabo M, et al. Targeting NK-cell checkpoints for cancer immunotherapy. Curr Opin Immunol (2017) 45:73-81. doi: 10.1016/j.coi.2017.01.003

55. Kuzet SE, Gaggioli C. Fibroblast activation in cancer: when seed fertilizes soil. Cell Tissue Res (2016) 365(3):607-19. doi: 10.1007/s00441-016-2467-x

56. De Jaeghere EA, Denys HG, De Wever O. Fibroblasts Fuel Immune Escape in the Tumor Microenvironment. Trends Cancer (2019) 5(11):704-23. doi: 10.1016/j.trecan.2019.09.009

57. Yoshida GJ, Azuma A, Miura Y, Orimo A. Activated Fibroblast Program Orchestrates Tumor Initiation and Progression; Molecular Mechanisms and the Associated Therapeutic Strategies. Int J Mol Sci (2019) 20(9):2256. doi: 10.3390/ijms20092256

58. Murata T, Mekada E, Hoffman RM. Reconstitution of a metastatic-resistant tumor microenvironment with cancer-associated fibroblasts enables metastasis. Cell Cycle (Georgetown Tex) (2017) 16(6):533-5. doi: 10.1080/ 15384101.2017.1281486

59. Avery D, Govindaraju P, Jacob M, Todd L, Monslow J, Puré E. Extracellular matrix directs phenotypic heterogeneity of activated fibroblasts. Matrix Biol (2018) 67:90-106. doi: 10.1016/j.matbio.2017.12.003

60. Zhu Y, Herndon JM, Sojka DK, Kim KW, Knolhoff BL, Zuo C, et al. TissueResident Macrophages in Pancreatic Ductal Adenocarcinoma Originate from Embryonic Hematopoiesis and Promote Tumor Progression. Immunity (2017) 47(2):323-38.e6. doi: 10.1016/j.immuni.2017.07.014

61. Guo S, Deng CX. Effect of Stromal Cells in Tumor Microenvironment on Metastasis Initiation. Int J Biol Sci (2018) 14(14):2083-93. doi: 10.7150/ ijbs. 25720

62. Zhu Y, Zhang L, Zha H, Yang F, Hu C, Chen L, et al. Stroma-derived Fibrinogen-like Protein 2 Activates Cancer-associated Fibroblasts to Promote Tumor Growth in Lung Cancer. Int J Biol Sci (2017) 13(6):80414. doi: $10.7150 /$ ijbs. 19398

63. Liu T, Han C, Wang S, Fang P, Ma Z, Xu L, et al. Cancer-associated fibroblasts: an emerging target of anti-cancer immunotherapy. J Hematol Oncol (2019) 12(1):86. doi: 10.1186/s13045-019-0770-1

64. Takai K, Le A, Weaver VM, Werb Z. Targeting the cancer-associated fibroblasts as a treatment in triple-negative breast cancer. Oncotarget (2016) 7(50):82889-901. doi: 10.18632/oncotarget.12658

65. Kozono S, Ohuchida K, Eguchi D, Ikenaga N, Fujiwara K, Cui L, et al. Pirfenidone inhibits pancreatic cancer desmoplasia by regulating stellate cells. Cancer Res (2013) 73(7):2345-56. doi: 10.1158/0008-5472.Can-123180

66. Azuma A. Pirfenidone treatment of idiopathic pulmonary fibrosis. Ther Adv Respir Dis (2012) 6(2):107-14. doi: 10.1177/1753465812436663

67. Komohara $Y$, Jinushi M, Takeya M. Clinical significance of macrophage heterogeneity in human malignant tumors. Cancer Sci (2014) 105(1):1-8. doi: $10.1111 /$ cas.12314

68. Chen X, Wang Y, Nelson D, Tian S, Mulvey E, Patel B, et al. CCL2/CCR2 Regulates the Tumor Microenvironment in HER-2/neu-Driven Mammary Carcinomas in Mice. PloS One (2016) 11(11):e0165595. doi: 10.1371/ journal.pone.0165595

69. Goerdt S, Orfanos CE. Other functions, other genes: alternative activation of antigen-presenting cells. Immunity (1999) 10(2):137-42. doi: 10.1016/s10747613(00)80014-x

70. Nejman D, Livyatan I, Fuks G, Gavert N, Zwang Y, Geller LT, et al. The human tumor microbiome is composed of tumor type-specific intracellular bacteria. Science (New York NY) (2020) 368(6494):973-80. doi: 10.1126/ science.aay9189

71. Ren F, Fan M, Mei J, Wu Y, Liu C, Pu Q, et al. Interferon- $\gamma$ and celecoxib inhibit lung-tumor growth through modulating $\mathrm{M} 2 / \mathrm{M} 1$ macrophage ratio in the tumor microenvironment. Drug Des Devel Ther (2014) 8:1527-38. doi: $10.2147 /$ dddt.S66302

72. Gordon S. Alternative activation of macrophages. Nat Rev Immunol (2003) 3 (1):23-35. doi: 10.1038/nri978

73. Raber PL, Thevenot P, Sierra R, Wyczechowska D, Halle D, Ramirez ME, et al. Subpopulations of myeloid-derived suppressor cells impair $\mathrm{T}$ cell responses through independent nitric oxide-related pathways. Int J Cancer (2014) 134(12):2853-64. doi: 10.1002/ijc.28622

74. Gabrilovich DI, Ostrand-Rosenberg S, Bronte V. Coordinated regulation of myeloid cells by tumours. Nat Rev Immunol (2012) 12(4):253-68. doi: $10.1038 /$ nri3175

75. Nagaraj S, Gupta K, Pisarev V, Kinarsky L, Sherman S, Kang L, et al. Altered recognition of antigen is a mechanism of $\mathrm{CD} 8+\mathrm{T}$ cell tolerance in cancer. Nat Med (2007) 13(7):828-35. doi: 10.1038/nm1609

76. Srivastava MK, Sinha P, Clements VK, Rodriguez P, Ostrand-Rosenberg S. Myeloid-derived suppressor cells inhibit T-cell activation by depleting cystine and cysteine. Cancer Res (2010) 70(1):68-77. doi: 10.1158/00085472.Can-09-2587

77. Raber P, Ochoa AC, Rodríguez PC. Metabolism of L-arginine by myeloidderived suppressor cells in cancer: mechanisms of $\mathrm{T}$ cell suppression and therapeutic perspectives. Immunol Invest (2012) 41(6-7):614-34. doi: $10.3109 / 08820139.2012 .680634$

78. Zhu Y, Knolhoff BL, Meyer MA, Nywening TM, West BL, Luo J, et al. CSF1/ CSF1R blockade reprograms tumor-infiltrating macrophages and improves response to T-cell checkpoint immunotherapy in pancreatic cancer models. Cancer Res (2014) 74(18):5057-69. doi: 10.1158/0008-5472.Can-13-3723

79. Leone RD, Powell JD. Metabolism of immune cells in cancer. Nat Rev Cancer (2020) 20(9):516-31. doi: 10.1038/s41568-020-0273-y

80. Kouidhi S, Ben Ayed F, Benammar Elgaaied A. Targeting Tumor Metabolism: A New Challenge to Improve Immunotherapy. Front Immunol (2018) 9:353. doi: 10.3389/fimmu.2018.00353 
81. Wei F, Wang D, Wei J, Tang N, Tang L, Xiong F, et al. Metabolic crosstalk in the tumor microenvironment regulates antitumor immunosuppression and immunotherapy resisitance. Cell Mol Life Sci CMLS (2020). doi: 10.1007/ s00018-020-03581-0

82. Ohta A, Gorelik E, Prasad SJ, Ronchese F, Lukashev D, Wong MK, et al. A2A adenosine receptor protects tumors from antitumor T cells. Proc Natl Acad Sci U S A (2006) 103(35):13132-7. doi: 10.1073/pnas.0605251103

83. Domblides C, Lartigue L, Faustin B. Control of the Antitumor Immune Response by Cancer Metabolism. Cells (2019) 8(2):104. doi: 10.3390/ cells 8020104

84. Fischer K, Hoffmann P, Voelkl S, Meidenbauer N, Ammer J, Edinger M, et al. Inhibitory effect of tumor cell-derived lactic acid on human T cells. Blood (2007) 109(9):3812-9. doi: 10.1182/blood-2006-07-035972

85. Choi SY, Collins CC, Gout PW, Wang Y. Cancer-generated lactic acid: a regulatory, immunosuppressive metabolite? J Pathol (2013) 230(4):350-5. doi: $10.1002 /$ path. 4218

86. Khan MAW, Ologun G, Arora R, McQuade JL, Wargo JA. Gut Microbiome Modulates Response to Cancer Immunotherapy. Dig Dis Sci (2020) 65 (3):885-96. doi: 10.1007/s10620-020-06111-x

87. Shi N, Li N, Duan X, Niu H. Interaction between the gut microbiome and mucosal immune system. Mil Med Res (2017) 4:14. doi: 10.1186/s40779-0170122-9

88. Maynard CL, Elson CO, Hatton RD, Weaver CT. Reciprocal interactions of the intestinal microbiota and immune system. Nature (2012) 489 (7415):231-41. doi: 10.1038/nature11551

89. Wesemann DR, Portuguese AJ, Meyers RM, Gallagher MP, Cluff-Jones K, Magee JM, et al. Microbial colonization influences early B-lineage development in the gut lamina propria. Nature (2013) 501(7465):112-5. doi: 10.1038 /nature12496

90. Kau AL, Ahern PP, Griffin NW, Goodman AL, Gordon JI. Human nutrition, the gut microbiome and the immune system. Nature (2011) 474(7351):32736. doi: $10.1038 /$ nature 10213

91. Zeng MY, Cisalpino D, Varadarajan S, Hellman J, Warren HS, Cascalho M, et al. Gut Microbiota-Induced Immunoglobulin G Controls Systemic Infection by Symbiotic Bacteria and Pathogens. Immunity (2016) 44 (3):647-58. doi: 10.1016/j.immuni.2016.02.006

92. Sethi V, Kurtom S, Tarique M, Lavania S, Malchiodi Z, Hellmund L, et al. Gut Microbiota Promotes Tumor Growth in Mice by Modulating Immune Response. Gastroenterology (2018) 155(1):33-7.e6. doi: 10.1053/ j.gastro.2018.04.001

93. Zhang X, Liu Q, Liao Q, Zhao Y. Pancreatic Cancer, Gut Microbiota, and Therapeutic Efficacy. J Cancer (2020) 11(10):2749-58. doi: 10.7150/jca.37445

94. Ling Z, Shao L, Liu X, Cheng Y, Yan C, Mei Y, et al. Regulatory T Cells and Plasmacytoid Dendritic Cells Within the Tumor Microenvironment in Gastric Cancer Are Correlated With Gastric Microbiota Dysbiosis: A Preliminary Study. Front Immunol (2019) 10:533. doi: 10.3389/fimmu. 2019.00533

95. Ma W, Mao Q, Xia W, Dong G, Yu C, Jiang F. Gut Microbiota Shapes the Efficiency of Cancer Therapy. Front Microbiol (2019) 10:1050. doi: 10.3389/ fmicb.2019.01050

96. Erdman SE, Poutahidis T. Cancer inflammation and regulatory $\mathrm{T}$ cells. Int $\mathrm{J}$ Cancer (2010) 127(4):768-79. doi: 10.1002/ijc.25430

97. Erdman SE, Poutahidis T. Gut bacteria and cancer. Biochim Biophys Acta (2015) 1856(1):86-90. doi: 10.1016/j.bbcan.2015.05.007

98. Erdman SE, Rao VP, Olipitz W, Taylor CL, Jackson EA, Levkovich T, et al. Unifying roles for regulatory $\mathrm{T}$ cells and inflammation in cancer. Int $\mathrm{J}$ Cancer (2010) 126(7):1651-65. doi: 10.1002/ijc.24923

99. Lakritz JR, Poutahidis T, Levkovich T, Varian BJ, Ibrahim YM, Chatzigiagkos A, et al. Beneficial bacteria stimulate host immune cells to counteract dietary and genetic predisposition to mammary cancer in mice. Int J Cancer (2014) 135(3):529-40. doi: 10.1002/ijc.28702

100. Rao VP, Poutahidis T, Fox JG, Erdman SE. Breast cancer: should gastrointestinal bacteria be on our radar screen? Cancer Res (2007) 67 (3):847-50. doi: 10.1158/0008-5472.Can-06-3468

101. Poutahidis T, Haigis KM, Rao VP, Nambiar PR, Taylor CL, Ge Z, et al. Rapid reversal of interleukin-6-dependent epithelial invasion in a mouse model of microbially induced colon carcinoma. Carcinogenesis (2007) 28(12):261423. doi: $10.1093 /$ carcin/bgm180
102. Coffelt SB, Wellenstein MD, de Visser KE. Neutrophils in cancer: neutral no more. Nat Rev Cancer (2016) 16(7):431-46. doi: 10.1038/nrc.2016.52

103. Erdman SE, Rao VP, Poutahidis T, Rogers AB, Taylor CL, Jackson EA, et al. Nitric oxide and TNF-alpha trigger colonic inflammation and carcinogenesis in Helicobacter hepaticus-infected, Rag2-deficient mice. Proc Natl Acad Sci U S A (2009) 106(4):1027-32. doi: 10.1073/pnas.0812347106

104. Bald T, Quast T, Landsberg J, Rogava M, Glodde N, Lopez-Ramos D, et al. Ultraviolet-radiation-induced inflammation promotes angiotropism and metastasis in melanoma. Nature (2014) 507(7490):109-13. doi: 10.1038/ nature13111

105. Dumitru CA, Lang S, Brandau S. Modulation of neutrophil granulocytes in the tumor microenvironment: mechanisms and consequences for tumor progression. Semin Cancer Biol (2013) 23(3):141-8. doi: 10.1016/ j.semcancer.2013.02.005

106. Poutahidis T, Kearney SM, Levkovich T, Qi P, Varian BJ, Lakritz JR, et al. Microbial symbionts accelerate wound healing via the neuropeptide hormone oxytocin. PloS One (2013) 8(10):e78898. doi: 10.1371/ journal.pone.0078898

107. Varian BJ, Gourishetti S, Poutahidis T, Lakritz JR, Levkovich T, Kwok C, et al. Beneficial bacteria inhibit cachexia. Oncotarget (2016) 7(11):11803-16. doi: 10.18632/oncotarget.7730

108. Varian BJ, Poutahidis T, DiBenedictis BT, Levkovich T, Ibrahim Y, Didyk E, et al. Microbial lysate upregulates host oxytocin. Brain Behav Immun (2017) 61:36-49. doi: 10.1016/j.bbi.2016.11.002

109. Poutahidis T, Kleinewietfeld M, Erdman SE. Gut microbiota and the paradox of cancer immunotherapy. Front Immunol (2014) 5:157. doi: 10.3389/ fimmu.2014.00157

110. Mougiakakos D, Choudhury A, Lladser A, Kiessling R, Johansson CC. Regulatory T cells in cancer. Adv Cancer Res (2010) 107:57-117. doi: 10.1016/s0065-230x(10)07003-x

111. Nishikawa H, Sakaguchi S. Regulatory $\mathrm{T}$ cells in cancer immunotherapy. Curr Opin Immunol (2014) 27:1-7. doi: 10.1016/j.coi.2013.12.005

112. Wang YA, Li XL, Mo YZ, Fan CM, Tang L, Xiong F, et al. Effects of tumor metabolic microenvironment on regulatory T cells. Mol Cancer (2018) 17 (1):168. doi: 10.1186/s12943-018-0913-y

113. Erdman SE, Poutahidis T, Tomczak M, Rogers AB, Cormier K, Plank B, et al. $\mathrm{CD} 4+\mathrm{CD} 25+$ regulatory $\mathrm{T}$ lymphocytes inhibit microbially induced colon cancer in Rag2-deficient mice. Am J Pathol (2003) 162(2):691-702. doi: 10.1016/s0002-9440(10)63863-1

114. Rao VP, Poutahidis T, Ge Z, Nambiar PR, Boussahmain C, Wang YY, et al. Innate immune inflammatory response against enteric bacteria Helicobacter hepaticus induces mammary adenocarcinoma in mice. Cancer Res (2006) 66 (15):7395-400. doi: 10.1158/0008-5472.Can-06-0558

115. Mao K, Baptista AP, Tamoutounour S, Zhuang L, Bouladoux N, Martins AJ, et al. Innate and adaptive lymphocytes sequentially shape the gut microbiota and lipid metabolism. Nature (2018) 554(7691):255-9. doi: 10.1038/nature25437

116. Leschner S, Westphal K, Dietrich N, Viegas N, Jablonska J, Lyszkiewicz M, et al. Tumor invasion of Salmonella enterica serovar Typhimurium is accompanied by strong hemorrhage promoted by TNF-alpha. PloS One (2009) 4(8):e6692. doi: 10.1371/journal.pone.0006692

117. Pott J, Hornef M. Innate immune signalling at the intestinal epithelium in homeostasis and disease. EMBO Rep (2012) 13(8):684-98. doi: 10.1038/ embor.2012.96

118. Macpherson AJ, Yilmaz B, Limenitakis JP, Ganal-Vonarburg SC. IgA Function in Relation to the Intestinal Microbiota. Annu Rev Immunol (2018) 36:359-81. doi: 10.1146/annurev-immunol-042617-053238

119. Donaldson GP, Ladinsky MS, Yu KB, Sanders JG, Yoo BB, Chou WC, et al. Gut microbiota utilize immunoglobulin A for mucosal colonization. Science (New York NY) (2018) 360(6390):795-800. doi: 10.1126/science.aaq0926

120. Roy S, Trinchieri G. Microbiota: a key orchestrator of cancer therapy. Nat Rev Cancer (2017) 17(5):271-85. doi: 10.1038/nrc.2017.13

121. Xia Y, Shen S, Verma IM. NF- $\mathrm{KB}$, an active player in human cancers. Cancer Immunol Res (2014) 2(9):823-30. doi: 10.1158/2326-6066.Cir-14-0112

122. Harrington BS, Annunziata CM. NF- $\mathrm{KB}$ Signaling in Ovarian Cancer. Cancers (2019) 11(8):1182. doi: 10.3390/cancers11081182

123. Shalapour S, Karin M. Cruel to Be Kind: Epithelial, Microbial, and Immune Cell Interactions in Gastrointestinal Cancers. Annu Rev Immunol (2020) 38:649-71. doi: 10.1146/annurev-immunol-082019-081656 
124. Jackstadt R, van Hooff SR, Leach JD, Cortes-Lavaud X, Lohuis JO, Ridgway RA, et al. Epithelial NOTCH Signaling Rewires the Tumor Microenvironment of Colorectal Cancer to Drive Poor-Prognosis Subtypes and Metastasis. Cancer Cell (2019) 36(3):319-36.e7. doi: 10.1016/ j.ccell.2019.08.003

125. Rooks MG, Garrett WS. Gut microbiota, metabolites and host immunity. Nat Rev Immunol (2016) 16(6):341-52. doi: 10.1038/nri.2016.42

126. Poutahidis T, Kleinewietfeld M, Smillie C, Levkovich T, Perrotta A, Bhela S, et al. Microbial reprogramming inhibits Western diet-associated obesity. PloS One (2013) 8(7):e68596. doi: 10.1371/journal.pone.0068596

127. Poutahidis T, Varian BJ, Levkovich T, Lakritz JR, Mirabal S, Kwok C, et al. Dietary microbes modulate transgenerational cancer risk. Cancer Res (2015) 75(7):1197-204. doi: 10.1158/0008-5472.Can-14-2732

128. Flint HJ, Scott KP, Louis P, Duncan SH. The role of the gut microbiota in nutrition and health. Nat Rev Gastroenterol Hepatol (2012) 9(10):577-89. doi: 10.1038/nrgastro.2012.156

129. Nicholson JK, Holmes E, Kinross J, Burcelin R, Gibson G, Jia W, et al. Hostgut microbiota metabolic interactions. Science (New York NY) (2012) 336 (6086):1262-7. doi: 10.1126/science.1223813

130. Clemente JC, Ursell LK, Parfrey LW, Knight R. The impact of the gut microbiota on human health: an integrative view. Cell (2012) 148(6):125870. doi: 10.1016/j.cell.2012.01.035

131. Yoshimoto S, Loo TM, Atarashi K, Kanda H, Sato S, Oyadomari S, et al. Obesity-induced gut microbial metabolite promotes liver cancer through senescence secretome. Nature (2013) 499(7456):97-101. doi: 10.1038/ nature12347

132. Soysal SD, Tzankov A, Muenst SE. Role of the Tumor Microenvironment in Breast Cancer. Pathobiology (2015) 82(3-4):142-52. doi: 10.1159/000430499

133. Wang Y, Mumm JB, Herbst R, Kolbeck R, Wang Y. IL-22 Increases Permeability of Intestinal Epithelial Tight Junctions by Enhancing Claudin-2 Expression. J Immunol (Baltimore Md 1950) (2017) 199 (9):3316-25. doi: 10.4049/jimmunol.1700152

134. Thirunavukkarasan M, Wang C, Rao A, Hind T, Teo YR, Siddiquee AA, et al. Short-chain fatty acid receptors inhibit invasive phenotypes in breast cancer cells. PloS One (2017) 12(10):e0186334. doi: 10.1371/journal.pone.0186334

135. Davie JR. Inhibition of histone deacetylase activity by butyrate. J Nutr (2003) 133(7 Suppl):2485s-93s. doi: 10.1093/jn/133.7.2485S

136. Louis P, Flint HJ. Diversity, metabolism and microbial ecology of butyrateproducing bacteria from the human large intestine. FEMS Microbiol Lett (2009) 294(1):1-8. doi: 10.1111/j.1574-6968.2009.01514.x

137. Zgouras D, Wächtershäuser A, Frings D, Stein J. Butyrate impairs intestinal tumor cell-induced angiogenesis by inhibiting HIF-1alpha nuclear translocation. Biochem Biophys Res Commun (2003) 300(4):832-8. doi: 10.1016/s0006-291x(02)02916-9

138. Payne CM, Weber C, Crowley-Skillicorn C, Dvorak K, Bernstein H, Bernstein $\mathrm{C}$, et al. Deoxycholate induces mitochondrial oxidative stress and activates NF-kappaB through multiple mechanisms in HCT-116 colon epithelial cells. Carcinogenesis (2007) 28(1):215-22. doi: 10.1093/carcin/ bgl139

139. Rodier F, Coppé JP, Patil CK, Hoeijmakers WA, Muñoz DP, Raza SR, et al. Persistent DNA damage signalling triggers senescence-associated inflammatory cytokine secretion. Nat Cell Biol (2009) 11(8):973-9. doi: $10.1038 /$ ncb1909

140. Beatty GL, Gladney WL. Immune escape mechanisms as a guide for cancer immunotherapy. Clin Cancer Res (2015) 21(4):687-92. doi: 10.1158/10780432.Ccr-14-1860

141. Hooper LV, Macpherson AJ. Immune adaptations that maintain homeostasis with the intestinal microbiota. Nat Rev Immunol (2010) 10 (3):159-69. doi: 10.1038/nri2710

142. Helmink BA, Khan MAW, Hermann A, Gopalakrishnan V, Wargo JA. The microbiome, cancer, and cancer therapy. Nat Med (2019) 25(3):377-88. doi: 10.1038/s41591-019-0377-7

143. McQuade JL, Daniel CR, Helmink BA, Wargo JA. Modulating the microbiome to improve therapeutic response in cancer. Lancet Oncol (2019) 20(2):e77-91. doi: 10.1016/s1470-2045(18)30952-5

144. Gopalakrishnan V, Spencer CN, Nezi L, Reuben A, Andrews MC, Karpinets TV, et al. Gut microbiome modulates response to anti-PD-1 immunotherapy in melanoma patients. Science (New York NY) (2018) 359(6371):97-103. doi: $10.1126 /$ science.aan 4236

145. Matson V, Fessler J, Bao R, Chongsuwat T, Zha Y, Alegre ML, et al. The commensal microbiome is associated with anti-PD-1 efficacy in metastatic melanoma patients. Science (New York NY) (2018) 359(6371):104-8. doi: $10.1126 /$ science.aao3290

146. Ngambenjawong C, Gustafson HH, Pun SH. Progress in tumor-associated macrophage (TAM)-targeted therapeutics. Adv Drug Deliv Rev (2017) 114:206-21. doi: 10.1016/j.addr.2017.04.010

147. Wculek SK, Cueto FJ, Mujal AM, Melero I, Krummel MF, Sancho D. Dendritic cells in cancer immunology and immunotherapy. Nat Rev Immunol (2020) 20(1):7-24. doi: 10.1038/s41577-019-0210-Z

148. Wang Y, Luan Z, Zhao C, Bai C, Yang K. Target delivery selective CSF-1R inhibitor to tumor-associated macrophages via erythrocyte-cancer cell hybrid membrane camouflaged $\mathrm{pH}$-responsive copolymer micelle for cancer immunotherapy. Eur J Pharm Sci (2020) 142:105136. doi: 10.1016/ j.ejps.2019.105136

149. Liu X, Pu Y, Cron K, Deng L, Kline J, Frazier WA, et al. CD47 blockade triggers $\mathrm{T}$ cell-mediated destruction of immunogenic tumors. Nat Med (2015) 21(10):1209-15. doi: 10.1038/nm.3931

150. Xu MM, Pu Y, Han D, Shi Y, Cao X, Liang H, et al. Dendritic cells but not macrophages sense tumor mitochondrial DNA for cross-priming through signal regulatory protein $\alpha$ signaling. Immunity (2017) 47(2):363-73.e5. doi: 10.1016/j.immuni.2017.07.016

151. Barclay AN, Van den Berg TK. The interaction between signal regulatory protein alpha (SIRP $\alpha$ ) and CD47: structure, function, and therapeutic target. Annu Rev Immunol (2014) 32:25-50. doi: 10.1146/annurev-immunol032713-120142

152. Majeti R, Chao MP, Alizadeh AA, Pang WW, Jaiswal S, Gibbs KDJr., et al. CD47 is an adverse prognostic factor and therapeutic antibody target on human acute myeloid leukemia stem cells. Cell (2009) 138(2):286-99. doi: 10.1016/j.cell.2009.05.045

153. Jaiswal S, Jamieson CH, Pang WW, Park CY, Chao MP, Majeti R, et al. CD47 is upregulated on circulating hematopoietic stem cells and leukemia cells to avoid phagocytosis. Cell (2009) 138(2):271-85. doi: 10.1016/ j.cell.2009.05.046

154. Tseng D, Volkmer JP, Willingham SB, Contreras-Trujillo H, Fathman JW, Fernhoff NB, et al. Anti-CD47 antibody-mediated phagocytosis of cancer by macrophages primes an effective antitumor T-cell response. Proc Natl Acad Sci U S A (2013) 110(27):11103-8. doi: 10.1073/pnas.1305569110

155. Furrie E, Macfarlane S, Kennedy A, Cummings JH, Walsh SV, O'Neil DA, et al. Synbiotic therapy (Bifidobacterium longum/Synergy 1) initiates resolution of inflammation in patients with active ulcerative colitis: a randomised controlled pilot trial. Gut (2005) 54(2):242-9. doi: 10.1136/ gut.2004.044834

156. Zhou S, Gravekamp C, Bermudes D, Liu K. Tumour-targeting bacteria engineered to fight cancer. Nat Rev Cancer (2018) 18(12):727-43. doi: $10.1038 / \mathrm{s} 41568-018-0070-\mathrm{z}$

157. Deng X, Tian H, Yang R, Han Y, Wei K, Zheng C, et al. Oral Probiotics Alleviate Intestinal Dysbacteriosis for People Receiving Bowel Preparation. Front Med (2020) 7:73. doi: 10.3389/fmed.2020.00073

158. Shi Y, Zheng W, Yang K, Harris KG, Ni K, Xue L, et al. Intratumoral accumulation of gut microbiota facilitates $\mathrm{CD} 47$-based immunotherapy via STING signaling. J Exp Med (2020) 217(5):e20192282. doi: 10.1084/ jem.20192282

159. Sharma P, Allison JP. The future of immune checkpoint therapy. Science (New York NY) (2015) 348(6230):56-61. doi: 10.1126/science.aaa8172

160. Sivan A, Corrales L, Hubert N, Williams JB, Aquino-Michaels K, Earley ZM, et al. Commensal Bifidobacterium promotes antitumor immunity and facilitates anti-PD-L1 efficacy. Science (New York NY) (2015) 350 (6264):1084-9. doi: 10.1126/science.aac4255

161. Vétizou M, Pitt JM, Daillère R, Lepage P, Waldschmitt N, Flament C, et al. Anticancer immunotherapy by CTLA-4 blockade relies on the gut microbiota. Science (New York NY) (2015) 350(6264):1079-84. doi: $10.1126 /$ science.aad 1329

162. Huang J, Jiang Z, Wang Y, Fan X, Cai J, Yao X, et al. Modulation of gut microbiota to overcome resistance to immune checkpoint blockade in cancer 
immunotherapy. Curr Opin Pharmacol (2020) 54:1-10. doi: 10.1016/ j.coph.2020.06.004

163. Chemnitz JM, Parry RV, Nichols KE, June CH, Riley JL. SHP-1 and SHP-2 associate with immunoreceptor tyrosine-based switch motif of programmed death 1 upon primary human $\mathrm{T}$ cell stimulation, but only receptor ligation prevents T cell activation. J Immunol (Baltimore Md 1950) (2004) 173 (2):945-54. doi: 10.4049/jimmunol.173.2.945

164. Jin Y, Dong H, Xia L, Yang Y, Zhu Y, Shen Y, et al. The Diversity of Gut Microbiome is Associated With Favorable Responses to Anti-Programmed Death 1 Immunotherapy in Chinese Patients With NSCLC. J Thorac Oncol (2019) 14(8):1378-89. doi: 10.1016/j.jtho.2019.04.007

165. Ji RR, Chasalow SD, Wang L, Hamid O, Schmidt H, Cogswell J, et al. An immune-active tumor microenvironment favors clinical response to ipilimumab. Cancer Immunol Immunother (2012) 61(7):1019-31. doi: 10.1007/s00262-011-1172-6

166. Spranger S, Spaapen RM, Zha Y, Williams J, Meng Y, Ha TT, et al. Upregulation of $\mathrm{PD}-\mathrm{L} 1, \mathrm{IDO}$, and $\mathrm{T}(\mathrm{regs})$ in the melanoma tumor microenvironment is driven by CD8(+) T cells. Sci Trans Med (2013) 5 (200):200ra116. doi: 10.1126/scitranslmed.3006504

167. Galon J, Bruni D. Approaches to treat immune hot, altered and cold tumours with combination immunotherapies. Nat Rev Drug Discov (2019) 18(3):197218. doi: 10.1038/s41573-018-0007-y

168. Noman MZ, Parpal S, Van Moer K, Xiao M, Yu Y, Viklund J, et al. Inhibition of Vps34 reprograms cold into hot inflamed tumors and improves anti-PD-1/PDL1 immunotherapy. Sci $A d v$ (2020) 6(18):eaax7881. doi: 10.1126/sciadv.aax7881

169. Parry RV, Chemnitz JM, Frauwirth KA, Lanfranco AR, Braunstein I, Kobayashi SV, et al. CTLA-4 and PD-1 receptors inhibit T-cell activation by distinct mechanisms. Mol Cell Biol (2005) 25(21):9543-53. doi: 10.1128/ mcb.25.21.9543-9553.2005

170. Dubin K, Callahan MK, Ren B, Khanin R, Viale A, Ling L, et al. Intestinal microbiome analyses identify melanoma patients at risk for checkpointblockade-induced colitis. Nat Commun (2016) 7:10391. doi: 10.1038/ ncomms10391

171. Dasgupta S, Erturk-Hasdemir D, Ochoa-Reparaz J, Reinecker HC, Kasper DL. Plasmacytoid dendritic cells mediate anti-inflammatory responses to a gut commensal molecule via both innate and adaptive mechanisms. Cell Host Microbe (2014) 15(4):413-23. doi: 10.1016/j.chom.2014.03.006

172. Kroemer G, Zitvogel L. Cancer immunotherapy in 2017: The breakthrough of the microbiota. Nat Rev Immunol (2018) 18(2):87-8. doi: 10.1038/nri.2018.4

173. Routy B, Le Chatelier E, Derosa L, Duong CPM, Alou MT, Daillère R, et al. Gut microbiome influences efficacy of PD-1-based immunotherapy against epithelial tumors. Science (New York NY) (2018) 359(6371):91-7. doi: $10.1126 /$ science.aan 3706

174. Urbancsek H, Kazar T, Mezes I, Neumann K. Results of a double-blind, randomized study to evaluate the efficacy and safety of Antibiophilus in patients with radiation-induced diarrhoea. Eur J Gastroenterol Hepatol (2001) 13(4):391-6. doi: 10.1097/00042737-200104000-00015

175. Salminen E, Elomaa I, Minkkinen J, Vapaatalo H, Salminen S. Preservation of intestinal integrity during radiotherapy using live Lactobacillus acidophilus cultures. Clin Radiol (1988) 39(4):435-7. doi: 10.1016/s0009-9260(88)80296-4

176. Delia P, Sansotta G, Donato V, Messina G, Frosina P, Pergolizzi S, et al. Prevention of radiation-induced diarrhea with the use of VSL\#3, a new highpotency probiotic preparation. Am J Gastroenterol (2002) 97(8):2150-2. doi: 10.1111/j.1572-0241.2002.05946.x

177. Yi X, Zhou H, Chao Y, Xiong S, Zhong J, Chai Z, et al. Bacteria-triggered tumor-specific thrombosis to enable potent photothermal immunotherapy of cancer. Sci $A d v$ (2020) 6(33):eaba3546. doi: 10.1126/sciadv.aba3546

178. Kroemer G, Galluzzi L, Kepp O, Zitvogel L. Immunogenic cell death in cancer therapy. Annu Rev Immunol (2013) 31:51-72. doi: 10.1146/annurevimmunol-032712-100008

179. Viaud S, Saccheri F, Mignot G, Yamazaki T, Daillère R, Hannani D, et al. The intestinal microbiota modulates the anticancer immune effects of cyclophosphamide. Science (New York NY) (2013) 342(6161):971-6. doi: $10.1126 /$ science. 1240537

180. Daisley BA, Chanyi RM, Abdur-Rashid K, Al KF, Gibbons S, Chmiel JA, et al. Abiraterone acetate preferentially enriches for the gut commensal Akkermansia muciniphila in castrate-resistant prostate cancer patients. Nat Commun (2020) 11(1):4822. doi: 10.1038/s41467-020-18649-5

181. Pushalkar S, Hundeyin M, Daley D, Zambirinis CP, Kurz E, Mishra A, et al. The Pancreatic Cancer Microbiome Promotes Oncogenesis by Induction of Innate and Adaptive Immune Suppression. Cancer Discovery (2018) 8 (4):403-16. doi: 10.1158/2159-8290.Cd-17-1134

182. Iida N, Dzutsev A, Stewart CA, Smith L, Bouladoux N, Weingarten RA, et al. Commensal bacteria control cancer response to therapy by modulating the tumor microenvironment. Science (New York NY) (2013) 342(6161):967-70. doi: $10.1126 /$ science. 1240527

183. Jenq RR, Taur Y, Devlin SM, Ponce DM, Goldberg JD, Ahr KF, et al. Intestinal Blautia Is Associated with Reduced Death from Graft-versus-Host Disease. Biol Blood Marrow Transplant (2015) 21(8):1373-83. doi: 10.1016/ j.bbmt.2015.04.016

184. DeBerardinis RJ. Tumor Microenvironment, Metabolism, and Immunotherapy. New Engl J Med (2020) 382(9):869-71. doi: 10.1056/NEJMcibr1914890

185. Ngiow SF, Young A. Re-education of the Tumor Microenvironment With Targeted Therapies and Immunotherapies. Front Immunol (2020) 11:1633. doi: $10.3389 /$ fimmu.2020.01633

186. Yadav M, Verma MK, Chauhan NS. A review of metabolic potential of human gut microbiome in human nutrition. Arch Microbiol (2018) 200 (2):203-17. doi: 10.1007/s00203-017-1459-x

187. De Angelis M, Garruti G, Minervini F, Bonfrate L, Portincasa P, Gobbetti M. The Food-gut Human Axis: The Effects of Diet on Gut Microbiota and Metabolome. Curr Med Chem (2019) 26(19):3567-83. doi: 10.2174/ 0929867324666170428103848

188. Kim S, Jazwinski SM. The Gut Microbiota and Healthy Aging: A MiniReview. Gerontology (2018) 64(6):513-20. doi: 10.1159/000490615

189. Wargo JA. Modulating gut microbes. Science (2020) 369(6509):1302-3. doi: $10.1126 /$ science.abc3965

190. Geirnaert A, Calatayud M, Grootaert C, Laukens D, Devriese S, Smagghe G, et al. Butyrate-producing bacteria supplemented in vitro to Crohn's disease patient microbiota increased butyrate production and enhanced intestinal epithelial barrier integrity. Sci Rep (2017) 7(1):11450. doi: 10.1038/s41598-017-11734-8

191. Hibberd AA, Lyra A, Ouwehand AC, Rolny P, Lindegren H, Cedgård L, et al. Intestinal microbiota is altered in patients with colon cancer and modified by probiotic intervention. BMJ Open Gastroenterol (2017) 4(1):e000145. doi: 10.1136/bmjgast-2017-000145

192. Cheng WY, Wu CY, Yu J. The role of gut microbiota in cancer treatment: friend or foe? Gut (2020) 69(10):1867-76. doi: 10.1136/gutjnl-2020-321153

193. Gharaibeh RZ, Jobin C. Microbiota and cancer immunotherapy: in search of microbial signals. Gut (2019) 68(3):385-8. doi: 10.1136/gutjnl-2018-317220

194. Kelly CR, Kahn S, Kashyap P, Laine L, Rubin D, Atreja A, et al. Update on Fecal Microbiota Transplantation 2015: Indications, Methodologies, Mechanisms, and Outlook. Gastroenterology (2015) 149(1):223-37. doi: 10.1053/j.gastro.2015.05.008

Conflict of Interest: The authors declare that the research was conducted in the absence of any commercial or financial relationships that could be construed as a potential conflict of interest.

Copyright (C) 2021 Qiu, Lin, Ma, Li, Liang, Chen, Liu, Huang, Luo, Huang and Luo. This is an open-access article distributed under the terms of the Creative Commons Attribution License (CC BY). The use, distribution or reproduction in other forums is permitted, provided the original author(s) and the copyright owner(s) are credited and that the original publication in this journal is cited, in accordance with accepted academic practice. No use, distribution or reproduction is permitted which does not comply with these terms. 